Portland State University

PDXScholar

Summer 10-1-2019

\title{
Urbanicity as a Moderator of the Relationship Between Stigma and Well-being Outcomes for Individuals with Serious Mental Illnesses
}

Emily Leickly

Portland State University

Follow this and additional works at: https://pdxscholar.library.pdx.edu/open_access_etds

Part of the Mental and Social Health Commons, and the Psychology Commons Let us know how access to this document benefits you.

\section{Recommended Citation}

Leickly, Emily, "Urbanicity as a Moderator of the Relationship Between Stigma and Well-being Outcomes for Individuals with Serious Mental Illnesses" (2019). Dissertations and Theses. Paper 5182.

https://doi.org/10.15760/etd.7058

This Thesis is brought to you for free and open access. It has been accepted for inclusion in Dissertations and Theses by an authorized administrator of PDXScholar. Please contact us if we can make this document more accessible: pdxscholar@pdx.edu. 
Urbanicity as a Moderator of the Relationship Between Stigma and Well-being

Outcomes for Individuals with Serious mental Illnesses

by
Emily Leickly

A thesis defense submitted in partial fulfillment of the requirements for the degree of

Master of Science

in

Psychology

Thesis Committee:

Greg Townley, Chair

Tessa Dover

Keith Kaufman

Portland State University

2019 


\begin{abstract}
During the deinstitutionalization movement in the 1960s, community mental health centers and supportive and affordable housing for people with serious mental illnesses (SMI) was concentrated in economically disadvantaged urban centers. Today, these urban centers are becoming increasingly gentrified and unaffordable for people with SMI. Affordability is no longer synonymous with urban living, and supportive housing for people with SMI is increasingly found in non-urban areas. Given this shift, it is important to understand the potential impacts of non-urban living on people with SMI. Non-urban environments provide potential benefits for the general population, including reduced traffic and increased proximity to the outdoors. However, people with SMI living in nonurban areas may perceive higher levels of mental illness stigma than their urban counterparts, leading to negative outcomes. I hypothesized that the relationships between perceived stigma and psychological distress and perceived stigma and sense of community would be moderated by urbanicity, such that these relationships would be stronger in non-urban settings. Data collected from 300 adults with SMI living in a range of urban and non-urban areas were analyzed using a moderated regression design. Correlations were found between primary study variables, but the moderation by urbanicity hypotheses were not supported. The broad construct of urbanicity needs to be explored further to understand which components impact perceived stigma and outcomes. The associations between urbanicity, perceived stigma, sense of community, and psychological distress support the need to address mental illness stigma across all settings.
\end{abstract}




\section{Acknowledgements}

My advisor, Dr. Greg Townley, has provided invaluable and unconditional support to me throughout this process. My committee members, Dr. Tessa Dover

and Dr. Keith Kaufman, have shared their expert input and guidance with me. My family, loved ones, and community of graduate students at Portland State University have encouraged and believed in me in every day.

The contents of this thesis were developed with the assistance of a grant from the National Institute on Disability, Independent Living, and Rehabilitation Research (NIDILRR; Grant \# 90RT5021-02-00; Mark Salzer, PI). However, the contents do not necessarily represent the policy of the U.S. Department of Health and Human Services, and endorsement by the Federal government should not be assumed. 


\section{Contents}

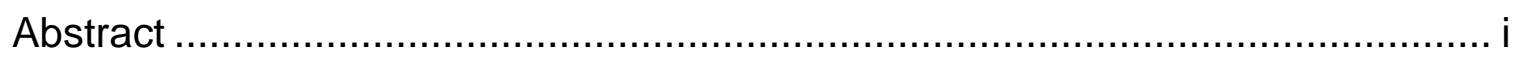

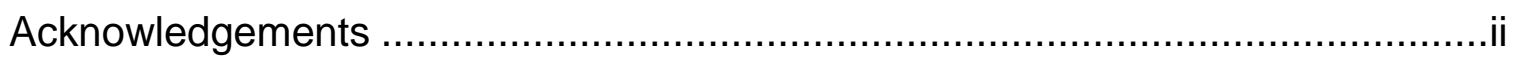

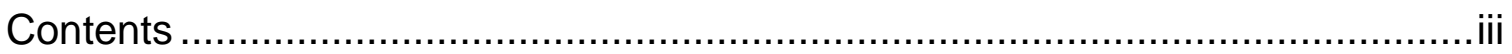

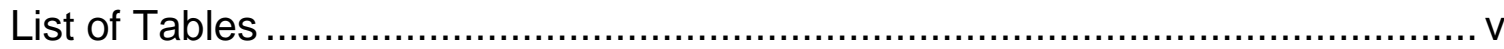

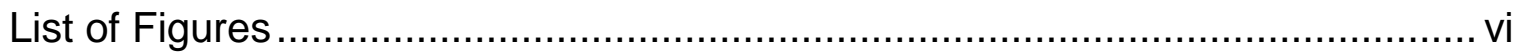

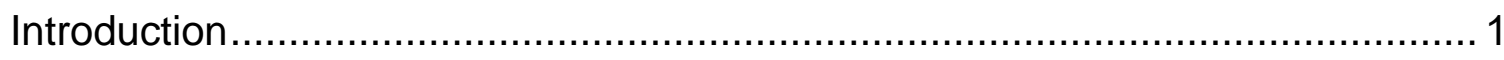

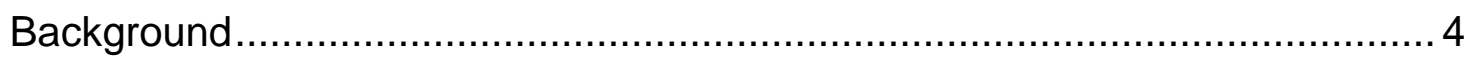

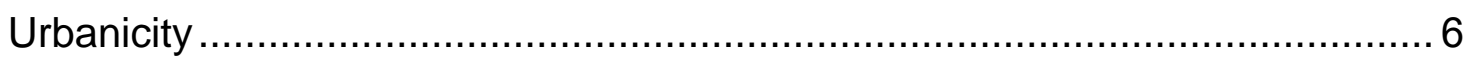

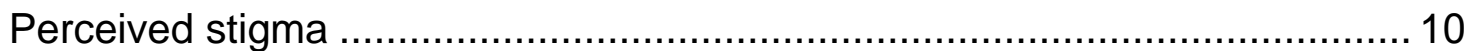

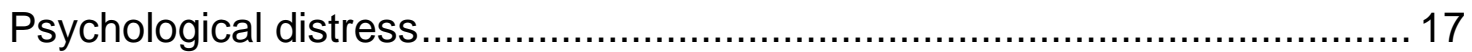

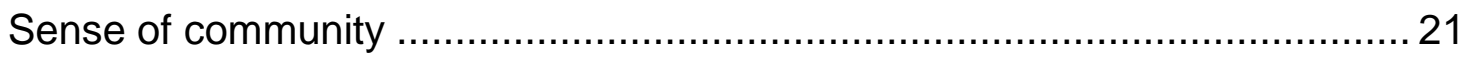

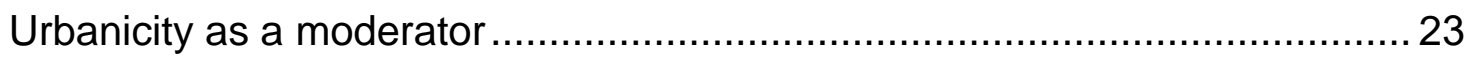

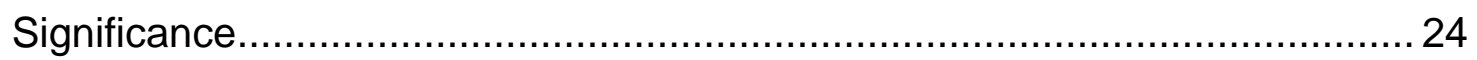

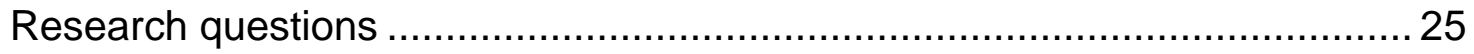

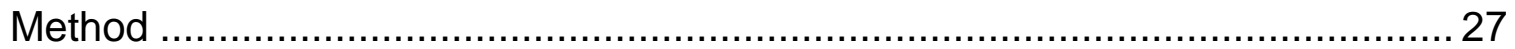

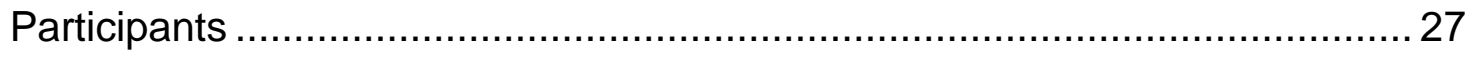

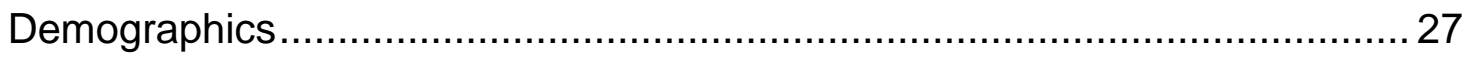

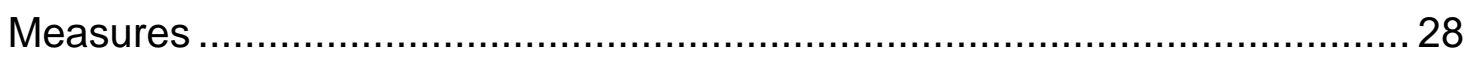

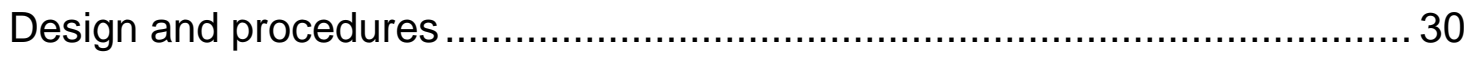

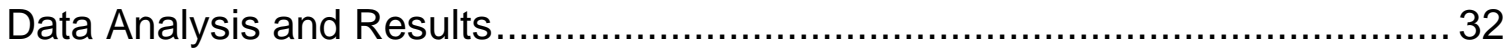

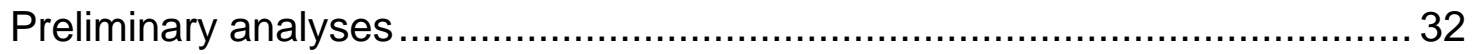

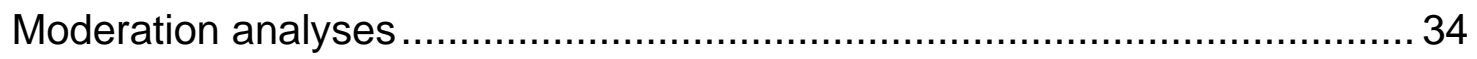

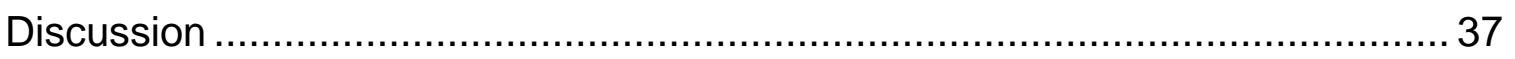

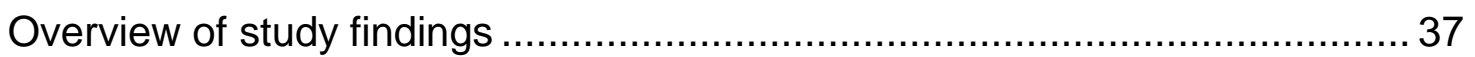

Limitations and future research directions ................................................. 41

Implications for research and practice .................................................. 46

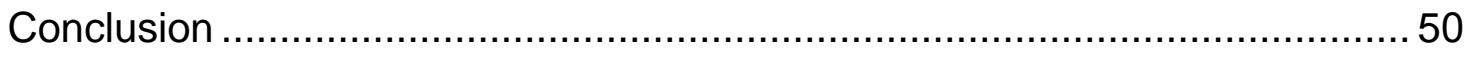

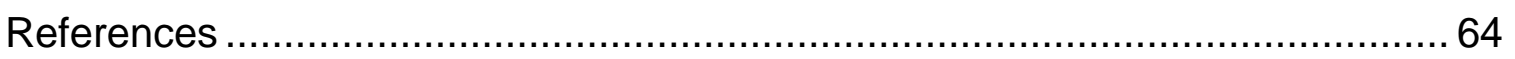

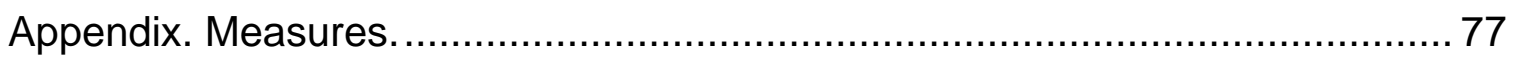

A.Rural-Urban Continuum Codes (Urbanicity) …....................................... 77 
B.Devaluation-Discrimination Scale (Perceived Stigma) ............................. 77

C.Hopkins Symptom Checklist (Psychological Distress) .............................. 80

D.Sense of Community Index - 2 (Sense of Community) ............................ 82 


\section{List of Tables}

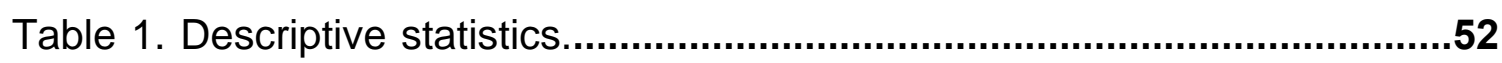

Table 2. Correlations between primary study variables...................................53

Table 3. Independent samples t-test: Outcome variables by gender..................54

Table 4. Independent samples t-test: Outcome variables by

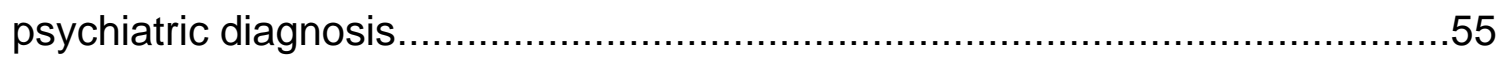

Table 5. Moderated regression 1 results (outcome: psychological distress)......56

Table 6. Moderated regression 2 results (outcome: sense of community).........57 


\section{List of Figures}

Figure 1. Proposed model of the relationship between perceived stigma and psychological distress as moderated by urbanicity.....

Figure 2. Proposed model of the relationship between perceived stigma and sense of community as moderated by urbanicity.

Figure 3. Recruitment diagram

Figure 4. Geographic location of study participants by levels of urbanicity

Figure 5. Moderated regression results for psychological

distress outcome 61

Figure 6. Moderated regression results for sense of community outcome. 62 
Urbanicity as a moderator of the relationship between stigma and well-being outcomes for individuals with serious mental illnesses

"Except when professional purposes are aligned with client interests, the service-dependent population is without the political power to demand greater assistance. Their needs fall by the wayside as the political- economic environment changes. In the process, the unfulfilled promise of community-based care may be quietly forgotten, crowded out by service delivery patterns that are less effective, less appropriate, and less humane." (Wolch \& Gabriel, 1984)

\section{Introduction}

Since the 1990s, there have been efforts by government to reduce public housing in city centers and prime the areas for gentrification (Reese, Deverteuil, \& Thach, 2010). However, displacement and dispersion of public housing does not reduce the need for it. As city centers become more expensive and desirable to the middle and upper classes, affordable housing is being pushed to less urban areas, such as suburban and rural locales, where access to services is limited (Dear \& Wolch, 1987; Yanos, 2007). The proportion of affluent white residents in historically affordable downtown neighborhoods is increasing (Katz \& Lang, 2003). This shift is particularly prominent on the West Coast. For example, the Northwest Pilot Project estimates that Portland, Oregon, has lost 863 lowincome housing units since 1974 (Ozawa, 2004). As a consequence, people with serious mental illnesses (SMI) seeking supportive or simply affordable housing 
may find their options increasingly limited to less urban areas. Because this shift in housing availability is guided by monetary concerns, rather than knowledge of best practices for people with SMI, investigation is needed on the experiences of this population in non-urban areas, both among individuals in supportive housing and also those living with family members or in their own housing.

People with SMI living farther away from city centers may find themselves enjoying the typically cited benefits of non-urban life: more spacious, less expensive living accommodations in a quieter setting with increased natural beauty and a tight-knit community where "everyone knows everyone." However, they may also find themselves exposed to a heavier burden of perceived stigma against people with mental illnesses. In addition to consequences related to perceived stigma, people with psychiatric disability have described other dilemmas and issues surrounding housing, including transportation and accessrelated barriers, unaffordability of preferred housing, and choosing between living in a location they liked versus near services they needed (Forchuk, Nelson, \& Brent Hall, 2006). These problems may be compounded in non-urban areas.

In the present line of research, I am interested in the particularly harsh effect perceived stigma may have on quality of life for people with SMI who live in non-urban areas, as opposed to urban areas. We must give attention to the unique experiences people with SMI may have in non-urban areas before assuming they will enjoy the same benefits of non-urban areas as the general population. I anticipate that, while stigma can be present in any environment, 
perceived stigma in non-urban areas will have more detrimental effects on psychological distress and sense of community for people with SMI, as compared to urban areas.

I will begin by providing background context regarding the shifting of mental health care for people with SMI from institutional settings to community settings, and the ensuing emphasis on community integration. The remainder of the introduction will be devoted to an in-depth examination of urbanicity (the proposed moderating variable), perceived stigma (the independent variable) and psychological distress and sense of community (the dependent or outcome variables). I will give a general overview of urbanicity and discuss the historical context of people with SMI living in urban areas. I will include material on the contrasting experiences of life in urban versus non-urban settings, and how living in areas with different levels of urbanicity differentially impacts the community experiences of people with SMI. Then I will provide an overview of perceived stigma and how it relates in general to the experience of SMI, as well as its effects on everyday life and well-being for people with SMI. Following this, I will present the literature connecting perceived stigma with psychological distress and discuss the myriad negative effects of psychological distress on mental and physical health outcomes. Next, I will provide a background overview of the sense of community construct, connecting it to other positive community-related and individual-level outcomes, as well as the potentially damaging effects of perceived stigma on sense of community. Finally, I will elucidate in more specific 
terms the significance of this line of research, and clearly state my research questions and hypotheses.

\section{Background}

SMI typically includes a diagnosis of major depressive disorder, bipolar disorders type I and II, and schizophrenia and schizophrenia-spectrum disorders. Characteristically, SMI involves a persistent psychiatric condition that significantly affects the person's thoughts, feelings, and behaviors, as well as their relationships and life opportunities (SAMHSA, 2017). According to the Substance Abuse and Mental Health Services Administration (SAMHSA), approximately four percent of all adults in the US were living with an SMI in 2016 (SAMHSA, 2017). People with SMI are a vulnerable population, often marginalized from society due to lack of economic power. The prevalence of medical conditions such as hypertension and metabolic syndrome is higher in people with SMI than in the general population (Coblentz et al., 2015; Janssen et al., 2015). Approximately $25 \%$ of adults with SMI reported utilizing subsidized housing (Pratt, 2012). Onethird reported living in poverty, and one-third had a history of homelessness (Pratt, 2012).

In the 1960s, the Community Mental Health Act and ensuing deinstitutionalization process established community mental health systems to replace inpatient institutions as the primary source of care for people with mental illnesses (Freedman \& Moran, 1984). Deinstitutionalization was championed in response to inhumane conditions and ineffective treatments being conducted at 
existing "mental hospitals" (Freedman \& Moran, 1984). An overarching goal was to prevent hospitalization as a go-to treatment for mental illness, and when hospitalization was unavoidable, to reduce the length of stays (Freedman \& Moran, 1984). An increased emphasis on the rights of people with mental illness made it more difficult to involuntarily commit people to institutions (Freedman \& Moran, 1984). Deinstitutionalization, along with the rise of psychopharmacology, also enabled huge cost savings for the government on the care of people with mental illnesses (Wolch \& Gabriel, 1984). While emphasizing the integration of people with mental illnesses into the community was long overdue, community mental health care systems continue to be chronically overburdened, and the promises of the deinstitutionalization movement have never been fully realized.

Supported housing options are increasingly being offered as alternatives to more formal residential facilities in the community for people with SMI. Supported housing emphasizes community integration, an essential component in the process of people with SMI becoming engaged in civic life (Townley, Kloos, \& Wright, 2009). Over the past two decades, researchers have developed the concept of community integration to include three components: physical integration, social integration, and psychological integration. Physical integration concerns participation of activities within the community, social integration deals with contact with other members of the community, and psychological integration refers to the individual's sense of community and belonging (Aubry \& Myner, 1996; Wong \& Solomon, 2002). 


\section{Urbanicity}

Defining urbanicity. Before discussing the impact of urbanicity on the community living experiences of adults with serious mental illnesses, it is first important to discuss the most common ways it is defined and measured. The United States Census Bureau defines urban areas as "densely developed territory, encompassing residential, commercial, and other non-residential land uses" (US Census Bureau, 2010). While the census dichotomizes urbanicity, the US Department of Agriculture provides a more nuanced picture of urbanicity by using a nine-point scale of Rural-Urban Continuum Codes (RUCCs; USDA Economic Research Service, 2013). The nine-point scale ranges from 1 (metropolitan counties with a population of one million or more) to 9 (nonmetropolitan counties that are completely rural or with a population less than 2,500, and not adjacent to a metropolitan area) (USDA Economic Research Service, 2013). As of 2010 , approximately $81 \%$ of people in the United States lived in urban areas, representing a $12 \%$ growth in the urban population since 2000 , and placing the other $19 \%$ of the population in areas classified as nonurban, or rural (US Census Bureau, 2010). Since 2010, growth rates of nonurban areas have continued to drop, barring a slight increase in 2016. As of $2017,14 \%$ of US residents live in non-urban counties, spread out over $72 \%$ of the land in the country (USDA Economic Research Service, 2013).

Urbanicity and SMI. Deinstitutionalization gave rise to inner-city areas that came to be known as service-dependent ghettos (Wolch \& Gabriel, 1984). From 
their advent, community mental health programs were underfunded, uncoordinated, and overburdened (Warren, 1981). Inner city areas were also in economic decline due to suburbanization following World War II (Wolch \& Gabriel, 1984). Thus, community mental health centers began to concentrate in cheap, deteriorated inner city areas (Wolch \& Gabriel, 1984). The vast number of people with little economic power being released or diverted from inpatient psychiatric care created a great need for affordable housing, for which availability was also found in inner city urban areas (Wolch \& Gabriel, 1984). As time went on, people with SMI wishing to regularly visit community mental health centers continued to require housing within a short distance, and community mental health centers were increasingly intentionally restricted from expanding to neighborhoods of higher socioeconomic level due to their perceived undesirability among residents of these neighborhoods (Wolch \& Gabriel, 1984). Through this convergence of multiple societal forces, service-dependent areas became common in the inner cities, where housing occupied by people with SMI clustered near community mental health services. (Wolch \& Gabriel, 1984).

Urban areas have generally been characterized as stressful to live in due to factors such as noise, pollution, and crowding (Fischer, 1975; Wirth, 1938), and are associated with increased psychiatric symptoms (Dhingra, Strine, Holt, Berry, \& Mokdad, 2009; Gong, Palmer, Gallacher, Marsden, \& Fone, 2016; Lederbogen et al., 2011). Prevalence of psychiatric disorders is higher in urban areas, such that researchers have begun to identify urbanicity, in combination 
with other factors, as a cause of schizophrenia in urban residents (Krabbendam \& van Os, 2005; Peen, Schoevers, Beekman, \& Dekker, 2010; van Os, Kenis, \& Rutten, 2010). Originally, this enduring correlation between urban living and schizophrenia was thought to be a result of people with schizophrenia seeking the services provided in urban areas. However, a large study of Swedish men found that the incidence of schizophrenia was higher among men who grew up in cities than those who grew up in non-urban areas (Lewis \& David, 1992). A Danish population study also found that people who lived in urbanized areas for sustained periods of time during childhood and adolescence had an increased risk of schizophrenia (Pedersen, 2001). This association has persisted despite analyses accounting for other factors such as family history of psychiatric disorder, and cannabis use (Lewis \& David, 1992; Mortensen, 2000).

Rural implications. As affordable housing is increasingly being pushed from city centers as part of a widespread effort to remake cities to attract greater affluence, it may become more common for supportive housing to be located in cheaper, non-urban areas (Newman \& Wyly, 2006; Wyly \& Hammel, 2005; Yanos, 2007). Placement of supportive housing for people with SMI in non-urban settings removes them from the sometimes taxing experience of city life. In a qualitative study, people with schizophrenia living in rural areas identified the calmer nature of their communities, particularly fewer crowds and less traffic, as aiding in stress reduction (Coblentz et al., 2015). Rates of depression are lower among people living in non-urban settings (Romans, Cohen, \& Forte, 2011). 
Proximity to nature, time spent outdoors, and everyday exposure to natural elements have been consistently linked to positive effects on mental and physical health (Russell et al., 2013). It must be noted that not all residents of non-urban areas live directly surrounded by nature, particularly those residing in semideveloped urban-adjacent areas; however, they are still more likely than city dwellers to be in close proximity to non-developed green spaces.

The lower population density of non-urban areas encourages social cohesion and connection among residents, helping to build sense of community (Ziersch, Baum, Darmawan, Kavanagh, \& Bentley, 2009). Non-urban areas may also have more stable social structures, and thus a stronger sense of community than urban areas where mobility is common due to transportation access and employment opportunities (Sonn, Bishop, \& Drew, 1999). Individuals residing in tight-knit non-urban communities may also experience higher levels of social support. People with SMI have cited family involvement and support as a benefit of non-urban living (Coblentz et al., 2015; Forchuk et al., 2006). Social support is often conceptualized as a protective factor against psychological distress and has been associated with improved mental health outcomes (Hefner \& Eisenberg, 2009). Conversely, decreased social support has been associated with increased psychological distress (Holahan \& Moos, 1981). Provided people with SMI are able to access the close social networks common to non-urban areas, there should theoretically be opportunities to encourage connection in these locales. 
When people with SMI are able to access healthcare in non-urban areas, they may have better experiences with their providers compared to people with SMI living in urban areas. Healthcare consumers with schizophrenia in rural areas felt that healthcare providers had more time for patients, were more flexible, and were more able and willing to foster a personal connection and "go the extra mile" (Coblentz et al., 2015). This type of healthcare environment may be more comfortable for people with SMI and thus encourage increased utilization of healthcare and compliance with medical and psychiatric care recommendations. Crowded urban clinics may unintentionally alienate people with SMI; and time and resource constraints may preclude the development of a health-promoting doctor-patient relationship.

Now that potential benefits of non-urban environments have been discussed, I will turn to the potential risks of non-urban residence by discussing primary study variables (perceived stigma, psychological distress, and sense of community) and the potential role of urbanicity in understanding the associations between these variables.

\section{Perceived stigma}

Health outcomes. Stigma is a deeply ingrained component of the experience of mental illness. To labeling theorists, stigma is inherent in the label of "mentally ill" (Rosenfield, 1997). They would argue that, functionally, people with SMI deal with two conditions: their psychiatric symptoms, and the experiences of stigmatization and discrimination based on their diagnosis 
(Rosenfield, 1997). The more people with mental illness identify with the stigmatized role of psychiatric patient, the more adversely the stigma will affect their day to day life, including their sense of belonging in the community (Robey, 1994). According to modified labelling theory, this stigma damages the selfesteem and self-efficacy of people who are identified as having mental illnesses (Link, 1987; Wahl \& Harman, 1989). Thus, labeling itself may further exacerbate the mental illness. One critical aspect of modified labeling theory is the focus on people with mental illnesses' perceptions of stigma rather than specific experiences of stigmatization or discrimination. Labeling theorists argue that perceptions of stigma and perceptions of experiences stemming from stigma have more impact on individual's psychological well-being than the discriminatory experience itself (Link, 1987).

Stigma affects every level of the lives of people with SMI. Due to stigma, people with SMI report experiencing disempowerment, diminished credibility, and avoidance by others (Pinfold, Byrne, \& Toulmin, 2005). Upon sharing an SMI diagnosis, they experience discrimination and different treatment from neighbors, landlords, family, and employers (Schulze \& Angermeyer, 2003). When people with SMI receive psychiatric and physical care, they are treated differently by providers (González-Torres, Oraa, Arístegui, Fernández-Rivas, \& Guimon, 2007). Mental health service providers tend to approach care for people with SMI, particularly schizophrenia, with a pessimistic prognosis and deny agency to consumers (González-Torres et al., 2007). Physicians tend to underestimate 
somatic complaints of people with schizophrenia, not taking them seriously and assuming that their mental illness causes them to exaggerate or invent symptoms (González-Torres et al., 2007; Schulze \& Angermeyer, 2003). In qualitative interviews, some family members of individuals with schizophrenia reported believing that community mental health organizations focus on crisis management rather than prevention and maintenance; that psychiatrists focus on medication as a sole treatment; and that these inadequate approaches to care are a result of mental illness stigma within the care system itself (Angermeyer \& Dietrich, 2006; Pinfold et al., 2005).

Stigma in non-urban areas. While stigma can be present in any environment, people with SMI living in non-urban settings may accurately perceive more intense stigma against mental illness than people in urban settings (Stewart, Jameson, \& Curtin, 2015). Previously, in one of the few studies on this topic, Townley and colleagues surveyed individuals with SMI living in urban and rural areas throughout the US regarding their community living and participation experiences (Townley, Brusilovskiy, \& Salzer, 2017). They found that, while community participation, perceptions of neighborhood quality, and sense of community were higher in urban areas, perceptions of mental health stigma were higher in non-urban areas (Townley et al., 2017). Drawing on previous research, the authors explored possible explanations for the finding of higher perceived stigma in non-urban areas. They posited that it is possible that 
tight-knit non-urban communities may have more adverse reactions to people who are "out of the ordinary" (Parr, Philo, \& Burns, 2004).

Expanding on this idea, people living in sprawling or sparsely populated non-urban areas have fewer opportunities to encounter people with SMI. This makes stigma reduction more difficult, as according to Allport's contact hypothesis, sustained and positive contact between a marginalized group and the general community can help to reduce stigmatizing beliefs (Allport, 1954). Specifically, Allport stipulates that, to successfully reduce prejudice, the contact between groups must involve informal, personal interaction, equal status, intergroup cooperation or common goals, and mutual support of laws and customs (Allport, 1954). In the case of people with SMI making contact with other community members in non-urban areas, equal status may be difficult to attain as many people with SMI are of a lower socioeconomic level. Second, the authors suggested that, due to lower population density, opportunities for people with SMI to form supportive networks among one another are limited in nonurban areas. Lacking these peer relationships may leave people with SMI in nonurban areas more vulnerable to internalized stigma, which can contribute to an overall perception of mental health stigma (Corrigan, 2006).

Additional considerations include the fact that small communities also make anonymity more difficult, such that when an individual with SMI seeks mental health services, they may open themselves to further judgement and stigma (Gonzales, Yanos, Stefancic, \& Alexander, 2018). In fact, mental illness 
stigma has been identified as a major barrier to implementation and utilization of mental health services in non-urban areas (McDonel et al., 1997). Sommers and colleagues found that non-urban residents were more likely to utilize crisis and supportive housing services, compared to psychosocial support services (Sommers, 1989). In regions where independence, stoicism, and self-reliance are valued, help-seeking for psychological reasons may be seen as a last resort or a failure of character (Jorm, 2000). In a study of older adults in non-urban areas, $80 \%$ reported not seeking mental health services because "I should not need help" (Brenes, Danhauer, Lyles, Hogan, \& Miller, 2015). Other researchers have found that non-urban residents with a history of depression labeled others who sought professional help for depression more negatively than did urban residents (Rost, Smith, \& Taylor, 1993). People with mental illnesses may develop such self-stigma from internalizing the stigma they perceive in their lives (Watson, Corrigan, Larson, \& Sells, 2007). Self-stigma has a negative effect on quality of life and damages self-esteem and self-efficacy (Corrigan, Sokol, \& Rüsch, 2013; Watson et al., 2007). Self-stigma has been established as a barrier to mental health recovery, specifically because it impedes social inclusion and community integration (Chan \& Mak, 2014).

Because research specifically examining stigma toward people with SMI across different levels of urbanicity is limited, I have also drawn upon research using other variables that are associated with holding stigmatizing beliefs, or associated with non-urban residence. While imperfect, the use of these proxy 
variables for perceived stigma and urbanicity could help provide a richer context for my research questions.

First, a study conducted in Italy found that respondents in regions with low population density, as well as low education levels were more frightened by perceived unpredictability of people with schizophrenia (Magliano et al., 2004). A large phone survey on attitudes toward people with schizophrenia found that rural residents tended to be less knowledgeable regarding the causes of schizophrenia, and were more likely to believe people with schizophrenia were violent and had split personalities (Stuart \& Arboleda-Florez, 2001). Stigmatizing attitudes about mental illness have also been associated with neighborhood factors such as political conservatism and low socioeconomic status (Gonzales, Chan, \& Yanos, 2017). One need only look at an election map to see that political conservatism is more prevalent in non-urban areas (Buchanan et al., 2016). People who endorsed conservative political ideology were more likely to attribute the problems experienced by a person with mental illness to "bad character" (i.e., being lazy or immoral), making these issues within their control (Watson, Corrigan, \& Angell, 2005). Furthermore, the belief that mental illness is a character flaw indirectly affected support for legal coercion to force individuals into mental health treatment (Watson et al., 2005). Historically, non-urban areas have had disproportionate rates of poverty compared to urban areas in the U.S. (Duncan \& Tickamyer, 1988). While educational attainment is increasing in the rural U.S., it is still overall lower than urban areas, and lower educational 
attainment is associated with poverty (Marré, 2017). Higher level of attained education was associated with lower levels of stigma toward people with mental illnesses (Holman, 2015). Stigmatizing attitudes are typically lower when mental health literacy is higher (Holman, 2015), and mental health literacy is associated with education (Furnham, Annis, \& Cleridou, 2014).

The socioeconomic hardship experienced by many non-urban communities may contribute to outgroup discrimination against people with mental illnesses. Downward comparison theory posits that members of lowstatus groups will derogate members of lower-status outgroups in attempt to enhance their own well-being (Cadinu \& Reggiori, 2002). If people in non-urban communities believe they are perceived as inferior due to their lower socioeconomic status, it may lead them to derogate vulnerable members of their community, such as people with SMI.

Diversity and cultural values. The 2010 US Census reported that around $78 \%$ of the population in non-urban communities was white, compared to $64 \%$ of the population of the entire US (Housing Assistance Council, 2012). The lower level of diversity in non-urban areas has potential implications for community integration: Townley (2018) investigated factors associated with community integration using geospatial and qualitative methods and found that higher diversity in neighborhoods was associated with higher levels of community integration (Townley, 2018). The high proportion of white residents in non-urban areas may have other implications for people with SMI. As is the case for any 
other group, white/Caucasian individuals hold cultural values and beliefs that can inform their attitudes about people with mental illness (Abdullah \& Brown, 2011). In a review of mental illness stigma and ethno-cultural beliefs, the authors summarized that people of European descent tend to value independence, autonomy, competition, and materialism, and orient themselves toward the future (Abdullah \& Brown, 2011). Such cultural values may engender stigma toward people with serious mental illnesses. In a qualitative study, people with schizophrenia and their family members described these societal expectations focusing on achievement, competitiveness, economic success, and activity as contributing to stigmatization when people with schizophrenia are unable or uninterested in meeting such expectations. Many people with SMI who are on Social Security Disability Insurance (SSDI) do not live completely independently or have total financial autonomy. Obtaining and maintaining employment is difficult for many people with schizophrenia due to prolonged absences for psychiatric reasons (Schulze \& Angermeyer, 2003). SSDI status typically precludes full participation in the competitive workforce, and low fixed income limits material accumulation. SMI, particularly schizophrenia, is typically perceived as chronic and carrying a bleak prognosis, making a primarily futurebased orientation challenging. The experiences of mental health stigma described in this section have pernicious effects on well-being and community living outcomes, as will be discussed further in the next two sections.

\section{Psychological distress}


Links to perceived stigma. For people with mental illnesses, perceptions of stigma are linked to psychological distress (Quinn et al., 2014; Quinn \& Chaudoir, 2009). Even among people with mental illness symptoms below a clinical threshold, stigma can exacerbate psychological distress (Schibalski et al., 2017). This link is present for many other groups holding concealable stigmatized identities, as compared to visible stigmatized identities such as race or gender (Quinn \& Chaudoir, 2009). Among people with HIV, perceptions of stigma were associated with psychological distress (Herek, Saha, \& Burack, 2013). Among people with intellectual disabilities, self-reported stigma was positively associated with psychological distress (Ali, King, Strydom, \& Hassiotis, 2015). Adults experiencing homelessness also reported higher psychological distress in relation to perceived homelessness stigma (Weisz \& Quinn, 2017).

Health outcomes. Psychological distress is associated with a broad range of negative physical and mental health outcomes. For example, it has been associated with higher odds of hypertension (Ojike et al., 2016), as well as suicidal behavior (Tang, Byrne, \& Qin, 2018). Among people with chronic medical illnesses, psychological distress can lead to increased symptoms, impairment, and medical costs, and impede self-care behaviors including medication and treatment plan adherence (Katon \& Ciechanowski, 2002). People experiencing psychological distress are also more likely to report a higher number of physically and mentally unhealthy days, days where their activity was limited, and generally 
fair or poor health compared to people without severe psychological distress, demonstrating its impact on quality of life (Shih et al., 2018).

Severe psychological distress has also been associated with healthcare avoidance, wherein people who exhibit psychological distress were more likely to avoid visiting a doctor even when they suspected a visit was necessary (Ye, Shim, \& Rust, 2012). Psychological distress may impede seeking regular preventative care in particular, more so than acute or emergency care (Witt et al., 2009). If an individual is already experiencing high psychological distress, they may display more avoidant behaviors when seeking care for a stigmatized condition such as mental illness becomes necessary (Ye et al., 2012). It is likely that psychological distress also predicts poorer mental health treatment outcomes. This connection is difficult to identify in the literature as most studies on predictors of treatment outcomes utilize constructs related to specific psychiatric symptoms rather than psychological distress in general (McMahon, 2014). However, one study found that psychiatric inpatients with high psychological distress were more likely to engage in deliberate self-harm behaviors (Kashyap, Hooke, \& Page, 2015).

Psychological distress also has implications for substance use behaviors. Among people with SMI who also used stimulant drugs, self-reported psychological distress predicted a shorter duration of abstinence from drugs (Angelo et al., 2013). This finding could be interpreted in multiple ways, wherein people with SMI use drugs as a coping mechanism for psychological distress, or 
the experience of psychological distress in itself makes it more difficult to maintain abstinence from drugs. A population-based study found that individuals with serious psychological distress were significantly more likely to use tobacco currently or in their lifetime, and also experienced more severe tobacco dependence, including greater smoking urgency and difficulty quitting (Hagman, Delnevo, Hrywna, \& Williams, 2008). Participants also smoked more frequently when their psychological distress symptoms increased (Hagman et al., 2008). It is important to consider the impact of psychological distress on tobacco use given the extremely high rates of tobacco use among people with SMI, even as rates among the general population decline (Cook et al., 2014).

On a population level, psychological distress has been linked to mortality. A large longitudinal study examined psychological distress outcomes by gender and found that for men high levels of psychological distress raised the mortality risk from heart disease, and for women high levels of psychological distress increased their vulnerability to death from cancer (Ferraro \& Nuriddin, 2018). Finally, a meta-analysis including over 68,000 adults from the general population in England found psychological distress to be associated with an increase in mortality from all causes, including cardiovascular disease and cancer deaths (Russ et al., 2018). Psychological distress is clearly a pernicious effect of stigma, associated with negative mental and physical health outcomes, particularly for people with concealable stigmatized identities such as those with SMI (Quinn \& Chaudoir, 2009). 


\section{Sense of community}

Background. Sense of community is broadly defined as a feeling of belonging and membership in a larger group (Sarason, 1974). It has been expanded upon as including four essential components: 1) membership, 2) influence, 3) integration and fulfillment of needs, and 4) shared emotional connection (McMillan \& Chavis, 1986). Membership is defined as a sense of belonging, investment in one's involvement in a group, and a sense of security about one's position in the group (McMillan \& Chavis, 1986). Influence is a sense that the member matters to the group and the group matters to the members, and that the individual can make a difference within the group. Integration and fulfillment of needs deals with the group member feeling as though their interests are met by the group, and their membership in the group is positively reinforced. Shared emotional connection refers in large part to a shared history (either through participation or identification) between the group and its members, which strengthens the community.

The construct of sense of community has been criticized as being overly individualistic and Western-centric, as it is conceptualized and typically measured as an individual level variable, leaving little room to investigate the nature and strength of a community as a whole (Sonn et al., 1999). However, the individual nature of sense of community may make it ideal for understanding the experiences of people who are marginalized - specifically, identifying who does not have a sense of community (Sonn et al., 1999). Thus, it seems an 
appropriate variable to use when studying people with SMI, for whom stigma and exclusion are often prominent forces affecting their experiences in the community (Townley \& Kloos, 2011).

Psychosocial outcomes. Sense of community is a critical ingredient precluding participation and integration in one's community (Chavis \& Wandersman, 1990). Sense of community is positively associated with happiness and well-being (Davidson \& Cotter, 1991; Pretty, Conroy, Dugay, Fowler, \& Williams, 1996), and feelings of belonging (Sarason, 1974). Though limited research on sense of community has been conducted with non-Western samples, sense of community was positively related with social support and quality of life for Chinese people living in Hong Kong (Mak, Cheung, \& Law, 2009). We also know that, for people who are part of interdependent, cooperative cultural traditions, community integration can be an important component of recovery and well-being (Abdullah \& Brown, 2011; Subandi, 2015).

Links to perceived stigma. The effect of perceived stigma on sense of community is relevant because the social connections fostered by sense of community, belonging, and integration are important to the well-being of people with SMI, just as is the case with the general population (Kloos \& Townley, 2011). Perceived stigma has been negatively associated with several variables that are closely related to sense of community. Among people with SMI, as perceived stigma increased, community participation (Gonzales et al., 2018) and sense of belonging in the community (Prince \& Prince, 2002) decreased. 
Research on quality of life for people with SMI has identified stigma as an important barrier to community integration (Chan \& Mak, 2014). Exemplifying this, despite the power of community integration as a powerful component of recovery (Townley et al., 2009), adults with schizophrenia had rates of community integration approximately half that of peers without schizophrenia (Abdallah, Cohen, Sanchez-Almira, Reyes, \& Ramirez, 2009). Community integration has been associated with psychiatric symptomatology, wherein increased psychiatric symptoms negatively impacted community integration (Gulcur, Tsemberis, Stefancic, \& Greenwood, 2007). Abnormal facial movements, a side effect of some psychiatric medications, were associated with lower community integration, suggesting that visible behaviors commonly associated with SMI may attract stigmatizing attitudes and hinder community integration (Abdallah et al., 2009).

\section{Urbanicity as a moderator}

The proportion of people with SMI living in non-urban areas is comparable to the proportion of the general population living in non-urban areas (Townley et al., 2017). As supportive and affordable housing is pushed out of city centers, this number is likely to grow (Reese et al., 2010). Thus, it is increasingly important to understand the effect that non-urban settings have on the health and well-being of people with SMI. Non-urban settings boast several characteristics that could be beneficial for people with SMI, including social cohesion and sense of community encouraged by low population density (Ziersch et al., 2009), and a 
calmer environment with care providers who are less overworked (Coblentz et al., 2015). However, the enhanced effects of perceived stigma against mental illness in non-urban areas may prevent people with SMI from enjoying such unique characteristics. Perceptions of stigma are linked to heightened psychological distress and lowered sense of community (Prince \& Prince, 2002; Quinn \& Chaudoir, 2009), which in turn have serious mental and physical health consequences, particularly for people with SMI. If these relationships are moderated by urbanicity, we may be able to understand whether people with SMI living in non-urban areas are experiencing worse consequences of perceived stigma than their urban counterparts (see Figures 1 and 2).

\section{Significance}

The so-called urban-rural divide has been extensively researched in terms of poverty, education, race, and socioeconomic status for the general population (Duncan \& Tickamyer, 1988; United States Department of Agriculture Economic Research Service, 2017). While large scale population studies are useful for understanding general trends, the experiences of particular subgroups of people can be lost. Thus far, much of the research examining urbanicity and mental illness has focused on the incidences of mental illness by urbanicity, particularly the increased incidence of schizophrenia in urban areas (Krabbendam \& van Os, 2005; Pedersen, 2001; van Os et al., 2010), or examination of the lived experiences of people with SMI in non-urban areas (Parr et al., 2004). Some researchers, particularly in the field of community psychology, have begun to 
compare the experiences people with SMI across urban and non-urban settings (Coblentz et al., 2015; Townley et al., 2017). Through this line of research, we may be able to better understand the experience of people with SMI living in nonurban areas, as well as how this experience compares to that of urban environments and what specific advantages and disadvantages the non-urban environment may present. Understanding the unique issues people with SMI face in non-urban environments is critical to addressing these problems and helping to improve their well-being and quality of life. The current study aims to contribute to this emerging area of research by testing the following research questions.

\section{Research questions}

Research question 1. What is the relationship between perceived stigma, psychological distress, and sense of community among people with SMI?

Hypothesis 1a: Higher levels of perceived stigma will be associated with increased psychological distress.

Hypothesis 1b: Higher levels of perceived stigma will be associated with decreased sense of community.

Research question 2. How does urbanicity affect the strength of the relationship between perceived stigma, psychological distress, and sense of community among people with SMI?

Hypothesis 2a: The relationship between perceived stigma and psychological distress will be positive and moderated by urbanicity, 
such that the relationship will be stronger in non-urban settings compared to urban settings.

Hypothesis 2b: The relationship between perceived stigma and sense of community will be negative and moderated by urbanicity, such that the relationship will be stronger in non-urban settings compared to urban settings. 


\section{Method}

\section{Participants}

The proposed study utilizes data from a survey of 300 adults with SMI receiving outpatient community mental health services at 21 organizations across 15 states (Townley, Brusilovskiy, \& Salzer, 2017). Organizations were selected based on their geographic location in order to maximize diversity in levels of urbanicity. Participating organizations distributed study fliers to potential participants in waiting rooms and common areas, and via case managers and staff. Interested participants called to be screened for the study.

Inclusion criteria were 1) aged between 18 and 65;2) confirmed diagnosis of a serious mental illness (schizophrenia-spectrum or major affective disorder); 3) self-reported mental-illness related limitations in the past 12 months (determined by asking, "has this mental health or emotional problem substantially interfered with or limited your ability to participate in any major life activities such as work, school, recreation, social activities, religious activities, family relationships, or caring for yourself within the past 12 months"); 4) eligibility for Medicaid or equivalent state program; and 5) provision of a residential address. Potential participants were excluded from the study if they were unable to provide informed consent or were under the care of a legal guardian. Figure 3 provides a recruitment diagram displaying the number of potential participants who did not continue on to be included in the study, and the reasons for their exclusion.

\section{Demographics}


Participants averaged 46 years old ( $S D=11.23$ years). Sixty percent identified as female and $40 \%$ identified as male. Sixty-five percent of participants identified as white, $28 \%$ identified as Black, $7 \%$ Latino or Hispanic, $1 \%$ Asian, $1 \%$ Native Hawaiian or other Pacific Islander, and 4\% Native American. These percentages total more than $100 \%$ because some participants reported more than one race/ ethnicity category. Two hundred and thirty participants (77\%) reported a major affective disorder diagnosis, and $128(43 \%)$ reported a schizophrenia-spectrum disorder diagnosis. Most participants (78\%) had a high school degree or higher, $32 \%$ were married or had a significant other, and $16 \%$ were working for pay. Finally, $56 \%$ of participants resided in a rented or owned apartment, home, or trailer; $22 \%$ resided in someone else's apartment, home or trailer; $21 \%$ in boarding homes or residential care facilities; and $1 \%$ of participants were homeless.

\section{Measures}

Urbanicity. Urbanicity was assessed using the U.S. Department of Agriculture's (USDA) measure of Rural-Urban Continuum Codes (RUCC). The RUCC is a continuous measure containing nine codes designating counties as most urban $(R \cup C C=1)$ to most rural $(R \cup C C=9)$ based on their population size and proximity to metropolitan areas. In the parent study that will supply the data for this proposed study, the RUCC was dichotomized due to low numbers of participants in some of the less urban categories (Townley et al., 2017). Thus, RUCCs of 1 and 2 were designated as urban (these categories contained 207 
participants [69\%] in the present study), and RUCCs of 3 to 9 were designated as non-urban (these categories contained 93 participants [31\%]). Counties in the urban category (RUCCs 1 and 2) ranged from 250,000 to one million people. Counties in the non-urban category (RUCCs 3-9) ranged from completely rural counties not adjacent to any metro county, to counties with 249,000 people. A USDA chart displaying the spread of RUCCs across the US can be found in the Appendix. Thus, in the proposed study, urbanicity will be conceptualized as a dichotomous variable with participants residing in urban or non-urban counties. See Figure 4 for a map in which participants' addresses were geocoded in ArcGIS and spatially matched with RUCC data obtained from the U.S. Department of Agriculture.

Perceived stigma. The 12-item Devaluation/Discrimination scale was used to measure perceived stigma (Link et al., 1989). The questions concern whether the participant believes that most people will devalue or discriminate against someone with a history of psychiatric treatment. It consists of 12 items, each answered on a six-point scale from "strongly disagree" (1) to "strongly agree" (6). Items are scored such that a high score reflects a high perception of stigma against people with SMI. The alpha for this scale was .76 (Link et al., 1989).

Psychological distress. Psychological distressed was measured using a 25-item version of the Hopkins Symptoms Checklist (HSCL-25; Derogatis, Lipman, Rickels, Uhlenhuth, \& Covi, 1974). Participants were read a list of psychological symptoms and rated on a four-point scale how stressful they found 
a particular symptom in the past week, from "not at all" (1) to "extremely" (4). An example item is "being scared for no reason." The scale was scored as an average of the 25 items. In this sample, internal reliability of the scale was .94 . The HSCL-25 has been used to measure psychological distress in various populations, and its validity is well-documented (Sandanger et al., 1998; Veijola et al., 2003).

Sense of community. Sense of community was assessed using the Sense of Community Index-2 (Chavis, Lee, \& Acosta, 2008). This measure consists of 24 statements regarding the four components of sense of community (membership, influence, fulfillment of needs, and shared emotional connection). Participants were asked to think about their own community and rate each statement on a four-point scale from "not at all" (1) to "completely" (4). An example item is "community members and I value the same things." In the dataset for this proposed study, a 13-item subset of the full measure was used due to phone survey time constraints. Items were selected based on relevance to individuals with SMI. The scale was scored as an average of the 13 items. The alpha for this scale in the present sample was .90 (Townley et al., 2017).

\section{Design and procedures}

The present cross-sectional study used survey-based methods and included measures of urbanicity, perceived stigma, psychological distress, and sense of community, as well as other measures assessing access to resources, Ioneliness, and quality of life. Phone interview techniques were used to collect 
data. Data were entered by research assistants directly into an online survey platform. Study interviews lasted approximately one hour. Participants were provided $\$ 20$ for their participation. The study was approved by the Institutional Review Boards of Portland State University and Temple University and, when required by partnering organizations, by the review boards within regional Departments of Mental Health. 


\section{Data Analysis and Results}

\section{Preliminary analyses}

Descriptive analyses in SPSS version 25 did not identify any significant issues with data entry, outliers, or missing data. The primary study variables (perceived stigma, psychological distress, and sense of community) were normally distributed (see Table 1). Skewness and kurtosis fell within the acceptable range, where absolute skewness values were under 3 and absolute kurtosis values were under 10 (Kline, 2011).

Use of the generalized linear model assumes that observations in analyses are independent and have uncorrelated error terms. Intraclass correlation coefficients (ICCs) were computed for the primary study variables to assess whether a multi-level model was needed to address potential bias introduced by the shared variance between participants utilizing services at the same agency or residing in the same state. ICCs for study variables were quite low (mean ICC $=.05$ at the agency and state level). In line with common recommendations in the literature that ICCs below .10 (i.e., $10 \%$ of the total variance in the outcome) are not likely to violate the independence assumption (e.g., Lee, 2000), we proceeded with analyses using a single-level model.

Point-biserial correlations were performed between the dichotomous urbanicity variable and the primary study variables (perceived stigma, psychological distress, and sense of community). Urbanicity (where $1=$ urban and $0=$ non-urban) was significantly negatively correlated with perceived stigma 
$(r=-.15, p<.05)$ and psychological distress $(r=-.14, p<.05)$, and significantly positively correlated with sense of community $(r=.19, p<.01)$. Perceived stigma was significantly positively correlated with psychological distress $(r=.39, p<.01)$ and significantly negatively correlated with sense of community $(r=.39, p<.01)$. Psychological distress was significantly negatively correlated with sense of community $(r=-.39, p<.01)$. A correlation matrix is presented in Table 2.

A series of t-tests and correlations were conducted between the outcome variables (psychological distress and sense of community) and demographic variables, including age, race, gender, and psychiatric diagnosis. These preliminary tests of association helped determine if any participant demographic variables should be included in the regression model as covariates, as has been suggested by prior research (Davis, Townley, \& Kloos, 2013). Age and race were not significantly associated with study outcome variables. Gender was significantly associated with study outcome variables (see Table 3). Women reported higher levels of psychological distress $(M=2.23, S D=.65)$ than men $(M$ $=1.89, S D=.60), t(294)=4.50, p<.001$. Women also reported lower levels of sense of community $(M=2.33, S D=.73)$ than men $(M=2.58, S D=.74), t(296)$ $=-2.89, p<.01$. Psychiatric diagnosis was also significantly associated with study outcome variables (see Table 4). Participants who reported a diagnosis of a schizophrenia-spectrum disorder reported lower psychological distress $(M=2.00$ $S D=.62)$ than participants without a schizophrenia-spectrum diagnosis $(M=$ $2.16, S D=.67), t(296)=2.11, p<.05$. Participants who reported a schizophrenia- 
spectrum diagnosis also endorsed higher levels of sense of community $(M=$ $2.56, S D=.76)$ than those without a schizophrenia-spectrum diagnosis $(M=$ 2.34, $S D=.70), t(298)=-2.64, p<.05$.

\section{Moderation analyses}

Data were analyzed in SPSS version 25, using Hayes' PROCESS macro (Hayes \& Little, 2018). A moderated multiple regression approach was used to examine group differences between participants in urban and non-urban areas. A moderator is a third variable that affects the strength of the relationship between an independent and a dependent variable (Baron \& Kenny, 1986; Cohen, Cohen, West, \& Aiken, 2003). Two moderated regression models were proposed: 1) the relationship between perceived stigma and psychological distress moderated by urbanicity, and 2) the relationship between perceived stigma and sense of community moderated by urbanicity (see Figures 1 and 2). Urbanicity was coded as 0 for urban and 1 for non-urban. For these hypotheses, a moderated regression analysis is thought to be superior to conducting dual correlations or separate regression analyses at each level of the moderator (Baron \& Kenny, 1986; Newsom, Prigerson, Schulz, \& Reynolds, 2003). The moderated regression approach is less vulnerable to issues such as group differences due to unequal sample sizes or sampling error, Type I error due to dichotomization, and inadequate control for variables confounded with group membership (Newsom et al., 2003). Given the dichotomization of urbanicity and unequal group sizes in this proposal, moderated regression is appropriate. 
Moderation model 1. The first moderated regression analysis was conducted with psychological distress as the outcome variable. Perceived stigma and urbanicity were mean-centered to reduce multicolinearity. Urbanicity and perceived stigma were entered into a main effects model. Based on earlier analyses of potential covariates, gender $(0=$ female; $1=$ male $)$ and psychiatric diagnosis $(0=$ non-schizophrenia spectrum diagnosis; 1 = schizophreniaspectrum diagnosis) were also entered into the main effects model. An interaction variable was computed by multiplying urbanicity and perceived stigma. This variable was entered into an interaction model, and regression analyses were conducted. Overall, this model predicted $18 \%$ of the variance in psychological distress. Psychiatric diagnosis and urbanicity did not predict psychological distress ( $p>.05)$. Gender predicted psychological distress $(B=-.20$, $\mathrm{SE}=.08,95 \% \mathrm{Cls}[-.35,-.05], \mathrm{p}<.05)$ as did perceived stigma $(\mathrm{B}=.22, \mathrm{SE}=.04$, $95 \% \mathrm{Cls}[.15, .29] \mathrm{p}<.001)$. Additionally, the interaction between perceived stigma and urbanicity was not significant, and the relationship between perceived stigma and psychological distress was not moderated by urbanicity $(B=-.06, S E=.08$, $95 \%$ Cls[-.21, .10, $p=.47)$.

Moderation model 2. Procedures for the second moderated regression were identical to the first, except for the use of sense of community as the outcome variable. Overall, this model predicted $18 \%$ of the variance in psychological distress. Psychiatric diagnosis and gender did not predict sense of community $(p>.05)$. Urbanicity predicted sense of community $(B=.19, S E=.09$, 
$95 \% \mathrm{Cls}[.02, .36], \mathrm{p}<.05)$, as did perceived stigma $(\mathrm{B}=-.26, \mathrm{SE}=.042,95 \%$ Cls[-.34, -.18], $p<.001$. The interaction between perceived stigma and urbanicity was not significant and the relationship between perceived stigma and sense of community was not moderated by urbanicity $(B=.04$, SE $=.09,95 \% \mathrm{Cls}[-.14$, .21 ], $p=.68$ ). See Figures 4 and 5 for graphs of the moderated regression results. 


\section{Discussion}

This study represents one of the first attempts to examine the effects of perceived mental illness stigma on the well-being of people with SMI across urban and non-urban settings. Perceptions of stigma can be associated with negative outcomes in any environment. However, people with SMI report increased perceptions of stigma in non-urban areas (Stewart et al., 2015; Townley et al., 2017). I hypothesized that perceived stigma would be associated with increased psychological distress and decreased sense of community, and would have more deleterious effects on psychological distress and sense of community in non-urban settings compared to urban settings.

\section{Overview of study findings}

Associations were found between the primary study variables. Living in urban settings was correlated with lower perceived stigma. This is consistent with the literature, where perceptions of mental illness stigma are higher in non-urban areas (Stewart et al., 2015). Living in urban settings was associated with lower psychological distress, seemingly in contrast with previous research's association between urban settings and increased psychiatric symptoms (Dhingra et al., 2009; Gong et al., 2016; Lederbogen et al., 2011). However, subtle differences exist between level of psychiatric symptomatology and psychological distress. An individual could theoretically experience high symptomatology (i.e., frequent hallucinations, manic episodes), but not report feelings of distress. Further 
exploration of the association between psychological distress and urbanicity is needed to better understand the finding.

Living in urban settings was also associated with a higher sense of community. This is contrary to previous research in samples without serious mental illnesses where living in non-urban settings was associated with a higher sense of community (Romans et al., 2011). This indicates that additional factors such as stigma toward mental illness may influence the development of sense of community for people with SMI in non-urban settings (Townley et al., 2017). Higher perceived stigma was correlated with higher psychological distress and lower levels of sense of community. The association between perceived stigma and psychological distress is documented in the literature (Quinn et al., 2014; Quinn \& Chaudoir, 2009). Perceived stigma has been previously associated with other community-related variables, and this finding regarding the specific construct of sense of community strengthens these links (Gonzales et al., 2018; Prince \& Prince, 2002). These findings also lend support to hypotheses $1 \mathrm{a}$ and 1b. Additionally, high psychological distress was correlated with lower sense of community. This is in line with previous studies reporting that higher psychiatric symptomatology and symptom distress are associated with lower sense of community and belonging for people with SMI (Gulcur et al., 2007; Kloos \& Townley, 2011).

Women reported higher levels of psychological distress and lower sense of community than men. This association between gender and psychological 
distress is reflected in the literature, where women typically report higher levels of psychological distress (Crisanti et al., 2017; Etopio, Devereux, \& Crowder, 2018) than men. Researchers have posited that this association may be moderated by variables related to the structural social disadvantages experienced by women, such as lower perceived safety (Etopio et al., 2018). This relationship could be exacerbated in women with SMI, who experience additional disadvantages due to their mental illness status. The reasons for the association between female gender and lower sense of community are less clear. Increased psychological distress could make it more difficult for women to form community. Further investigation is needed to understand sense of community among women with SMI. Additionally, in the present study all participants identified as male or female. There is a paucity of research in the field engaging people with SMI who are transgender, nonbinary, or gender-nonconforming.

Having a schizophrenia-spectrum disorder diagnosis was associated with lower psychological distress and higher sense of community, although diagnosis did not predict these outcomes when it was entered alongside other variables in the regression model. The literature offers a possible explanation for these correlational findings. People with schizophrenia have generally been found to exhibit poorer insight into their condition than those with schizoaffective disorder and major depression with psychotic features, though their insight was comparable to that of people with bipolar disorder (Pini, Cassano, Liliana Dell, \& Amador, 2001). Even if an individual is experiencing psychiatric symptoms, low 
insight regarding the symptoms' severity and their social ramifications may prevent the individual from experiencing significant psychological distress or lowered sense of community. However, the finding regarding sense of community differs from a previous study where having a psychotic or nonpsychotic mental illness diagnosis was not significantly related to sense of community among people with SMI (Townley \& Kloos, 2011). This indicates that other variables may be at play in this relationship; but without the inclusion of potential explanatory variables such as insight, it is difficult to draw strong conclusions.

In the moderated regression analyses, higher perceived stigma and female gender predicted higher psychological distress. Higher perceived stigma and living in a non-urban area predicted a lower sense of community. The finding that urbanicity did not predict psychological distress and instead predicted higher sense of community is potentially in contrast to previous assumptions and findings in the literature. This will be discussed further below. Support for hypotheses $1 \mathrm{a}$ and $1 \mathrm{~b}$ was present in these moderation findings, wherein perceived stigma predicted higher psychological distress and lower sense of community after controlling for covariates. However, the relationships between perceived stigma and psychological distress and perceived stigma and sense of community were not moderated by urbanicity. Thus, hypotheses $2 a$ and $2 b$ were not supported. The significance of main effects and non-significance of interactions indicates perceived stigma impacted psychological distress and 
sense of community at both levels of urbanicity, but the impact was not significantly different. Possible explanations of this will be discussed in more detail below.

\section{Limitations and future research directions}

While this study had notable strengths, a few limitations must also be discussed. First, I will discuss limitations that could provide specific insight into the non-significant moderation findings and create a path forward for the next line of inquiry. Then I will move on to more general limitations of the study methodology.

The role of the environment in mental illness stigma and outcomes for people with SMI is supported in the literature, where adults in rural environments report greater perceived mental illness stigma (Stewart et al., 2015; Townley et al., 2017). It is possible that the lack of support for urbanicity as a moderator in this study is related to the measure of urbanicity that was used (RUCC scores dichotomized into urban/non-urban categories) rather than the absence of an impact of urbanicity on the effects of perceived stigma for people with SMI. RUCC scores are based on population density and proximity to urban areas (USDA Economic Research Service, 2013). However, the concept of urbanicity in research and practice encompasses much more than density and proximity. There are many possible contributing factors or "critical ingredients" of urbanicity that could affect the experiences of people with SMI in a given locale.

Conceptually, I divide these ingredients into person-based/social factors and 
place-based/geographic factors. Person-based factors include conservative attitudes and population homogeneity. Place-based factors include availability and accessibility of social services and transportation. By this logic, a specific factor such as conservative attitudes toward people with mental illnesses may better predict the impact of perceived stigma on well-being outcomes than simply population density. In other words, the ingredient of urbanicity that predicts the impact of stigma on well-being could be conservative attitudes, rather than population density. Thus, further investigating these components of urbanicity may lead to selection of a more theoretically specific moderator. Furthermore, it may be worthwhile to conceptualize locales along continuums other than urbanicity when we think about the impact of the environment on people with SMI (L. Kriegel, personal communication, March 13, 2019). For example, a declining, impoverished city may have less access to transportation and mental health services than an economically stable rural community, leading to better outcomes for people with SMI in the rural community. In this case, categorizing these environments as rural or urban would not be an appropriate proxy for the resources available to people with SMI.

This study only engaged adults with SMI who were seeking community mental health services at participating organizations at the time of study recruitment. Fewer than $40 \%$ of adults with SMI are estimated to receive treatment (Kessler et al., 2001). The experiences of those who do not seek services is not explored in this study and may be substantially different from the 
service-engaged participants who were surveyed. In fact, it is possible that people with SMI who do not seek mental health services are experiencing exceptionally high levels of perceived stigma, and this stigma is a barrier to service utilization. Thus, the study lacks representative data from the larger group of adults with SMI who are not engaged in service use. Caution should be used when interpreting results as they may be generalizable only to people with SMI who are engaged with community mental health services, rather than all people with SMI. Additionally, characteristics and experiences may vary by diagnosis within the larger population of individuals with SMI, as discussed earlier in this section.

Researchers have raised concerns regarding the reliability and validity of self-report data collected from people with SMI, in particular those with schizophrenia-spectrum diagnoses (Atkinson, Zibin, \& Chuang, 1997). However, survey measures used with the general population have been found to be equally sound when conducted with people with SMI (Salyers, Bosworth, Swanson, Lamb-Pagone, \& Osher, 2000). People with schizophrenia are also able to provide reliable self-report information about their health service utilization (Goldberg, Seybolt, \& Lehman, 2002). According to labeling theory, perceptions of stigma develop in response to the sociocultural environment, rather than as a consequence of mental illness, making symptom severity or diagnosis unlikely influences on perceived stigma (Link, 1987). Consistent with this, Link found perceptions of stigma to be consistent across groups of participants with varying 
levels of psychiatric severity (Link, 1987). Additionally, the present study was conducted with a service engaged population of adults with SMI, who were accessing resources available at community mental health centers such as case management, peer support, and prescribers. It is unlikely that these individuals were experiencing symptomatology so extreme as to impact their ability to respond to survey questions. Thus, the quality of the data in this study was unlikely to have been compromised by the participants' SMI status.

As with many studies, there are potential third variables that could influence the variables of interest. Living situation could impact perceived stigma, and subsequently the consequences of perceived stigma, in several ways. Provided the family members are supportive, living with family members may be a protective factor against perceived stigma, compared to living alone. Residential tenure could also affect an individual's integration, or lack thereof, in a community, and therefore impact study variables. Individuals who have lived in a community for a long time may have more social connections and perceive greater community integration (Silverman \& Segal, 1994). There is a rich and growing body of literature on the impact of place and community-based factors on community integration of people with SMI (Kriegel, Townley, Brusilovskiy, \& Salzer, 2019; Townley \& Kloos, 2011; Townley et al., 2009). Integrating these findings with research on the role of urbanicity-related factors on the well-being of people with SMI would be a logical next step. 
This is a cross-sectional, correlational study, and causal relationships linking urbanicity to stigma, sense of community, and psychological distress should not be inferred. Longitudinal research would allow a better understanding of how these effects play out over time rather than just a snapshot. For example, researchers could follow people with SMI as they integrate into a new community. They could repeatedly measure outcome variables over an extended period of time for people with SMI living in areas that are experiencing rapid growth and urbanization. In the present study, the possible presence of confounding variables is an additional limitation in drawing conclusions about the relationships between perceived stigma and well-being outcomes across levels of urbanicity. Rather than perceived stigma, there may be other factors explaining increased psychological distress and low sense of community, including social isolation, or access to community mental health resources.

Finally, artificial dichotomization of the urbanicity variable was necessary, though not ideal, in the proposed study. Previous studies found that a continuous scale measure of urbanicity performed better than the typical urban vs. nonurban dichotomy (Dahly \& Adair, 2007). Another study found that using three groups (isolated rural, metropolitan-adjacent, and urban) yielded differing results in terms of self-stigma and indifference to stigma, yet both non-urban groups exhibited similarly high levels of public stigma compared to the urban group (Stewart et al., 2015), Unfortunately, in the present study if the RUCC had remained a continuous variable with 9 categories, there would have been very 
few (if any) participants in all 7 of the non-urban categories. In the future, a larger sample size would enable researchers to preserve the superior continuous version of the RUCC and examine more nuanced differences across all 9 levels of urbanicity.

With this recommendation, it is also important to acknowledge the challenges of accessing people with SMI in rural communities compared to urban. Many researchers are located at universities close to urban centers, and collaboration with local community mental health organizations is more easily accessible. Organizations in urban areas may also be more accustomed to working with researchers and ideologically receptive to research goals. As described earlier, rural communities tend to hold more conservative views. While these ideologies may not extend to rural service providers, they could still create a barrier to research collaboration. Community psychologists often have limited funding, and the costs of travel to less dense rural areas that yield lower numbers of participants can be difficult to financially. However, these very real challenges do not erase, and may instead exacerbate, the need for greater attention from researchers to people with SMI in non-urban areas. Increased efforts to involve non-urban populations with SMI would enable researchers to more thoroughly understand the experiences of people with SMI in suburban, or urban-adjacent areas - both growing urbanicity categories in the United States.

\section{Implications for research and practice}


This study was a timely exploration of the individual-level effects of urbanicity on people with SMI. As gentrification displaces affordable housing from urban centers, people with SMI may be increasingly likely to live in non-urban areas, making it important to understand their experiences across these different environments. Living in non-urban areas was associated with higher perceived stigma and psychological distress, and lower sense of community. However, these relationships were not sufficient to differentially predict the impact of perceived stigma on psychological distress and sense of community at the nonurban versus urban level. As this line of inquiry is relatively new, a qualitative approach, rather than a variable-centered quantitative approach, or utilization of place-based methods may have been more appropriate. A qualitative study could include interviews with people with SMI across different places on the urban-rural continuum, or with people with SMI who have had the experience of living in multiple places of varying levels of urbanicity. Researchers could also conduct an environmental audit of urban and non-urban spaces, assessing factors that may contribute to perceptions of stigma toward mental illness, create psychological distress, or enhance or hinder sense of community. An environmental audit could include examination of the built environment, as well as content analysis of public messaging around mental illness. Place-based methods such as activity spaces could be used to understand the differences in access and activities of people with SMI across urban and non-urban environments (see, for example, Townley et al., 2009). These methods can also provide insight into community integration 
and opportunities for contact between people with SMI and others in the community.

Nevertheless, these findings may prompt re-examination of assumptions about the type of environment most likely to support well-being for people with SMI and guide research questions when utilizing other methodologies. Urbanicity has long been conceptualized as psychologically detrimental to people with SMI. However, people with SMI in urban areas experience lower levels of public and self-stigma around mental illness than their non-urban counterparts (Stewart et al., 2015). Many urban areas offer greater access to the resources needed by this population, in part due to the historic placement of community mental health services in urban centers (Metraux, Brusilovskiy, Prvu-Bettger, Irene Wong, \& Salzer, 2012). Mental health professionals continue to be concentrated in urban counties with large populations and higher average income (Ellis, Konrad, Thomas, \& Morrissey, 2009). Indeed, a study examining shortages of mental health professionals across the US found that $77 \%$ of US counties had a shortage of providers, and rurality and per capita income were the strongest predictors of unmet need (Thomas, Ellis, Konrad, Holzer, \& Morrissey, 2009). When examining a county's RUCC, a 1 point increase (higher scores being more rural) corresponded to a 3.3\% increase in unmet need (Thomas et al., 2009). The overall number of providers with prescribing authority (i.e. psychiatrists, psychiatric nurses, and some clinical psychologists) is smaller than that of other mental health professionals, and there is a shortage of prescribers in non-urban 
areas (Ellis et al., 2009; Thomas et al., 2009). This has potentially negative implications for people with SMI, as psychiatric medication is often a component of treatment and recovery for these conditions. The community mental health centers that exist in non-urban areas remain geographically inaccessible to many people with SMI due to inadequate public transportation and lack of private transportation (Coblentz et al., 2015). Lack of transportation is also a barrier to accessing medical and social services, and it contributes to social isolation of people with SMI in non-urban settings (Coblentz et al., 2015).

Other first order change strategies such as interventions to reduce stigma, treatment considerations to alleviate psychological distress, and programs and environmental supports to bolster sense of community may be especially beneficial to people with SMI in non-urban areas. Structural stigma in the community (rather than perceived stigma) could be measured in a variety of ways. Structural stigma is defined as "societal-level conditions, cultural norms, and institutional policies that constrain the opportunities, resources, and wellbeing of the stigmatized" (Hatzenbuehler, 2016). To understand structural stigma, researchers could investigate community indicators, such as attitudes of community members without SMI regarding people with mental illness, through interviews, surveys, or analysis of social media posts. Researchers could also make efforts to learn about the attitudes of service providers and other individuals in the community who are likely to have frequent contact with individuals with SMI. The tenants of Allport's contact theory could be applied in 
public programming (Allport, 1954). Expanded research on contact theory has resulted in additional recommendations utilizing virtual or telecommunication contact strategies (Dovidio, Love, Schellhaas, \& Hewstone, 2017). These approaches could be particularly useful in non-urban areas with low population density and homogenous populations where encountering a person with SMI in everyday life is rare.

Additionally, continuing to integrate mental health services into primary care may provide people with SMI a more accessible and discreet avenue to seek treatment. The act of seeking mental health services was cited by people with SMI in non-urban areas as stigmatizing, and subsequently avoided (McDonel et al., 1997). With integrated mental health care, people with SMI would be able to access services without being in a situation where they would perceive stigma for help-seeking.

Planners and developers could also pay heed to structural and design characteristics of cities that foster contact between groups, and ensure such development occurs in non-urban areas as well as urban (Jacobs, 1961). Improving transportation options in non-urban areas could also alleviate the effects of perceived stigma by reducing barriers to care and aiding in social integration.

\section{Conclusion}

I investigated two potential effects of perceived mental illness stigma across urban and non-urban areas: increased psychological distress and 
reduced sense of community. A moderation effect was not found, but living in non-urban areas was associated with higher perceived stigma and psychological distress, and lower sense of community. Stigma itself is a symptom of social and economic inequality. Inequalities in our society too often result in the suffering of the most vulnerable members of our communities. Ultimately, inequality is a societal-level problem that requires societal-level, second-order change. Inequality will continue as long as cities remain unaffordable and people of lower economic status are seen as inferior. The ultimate task of community psychologists is to bring our findings to the attention of those most able to influence second-order changes in our communities and the country at large. With this in mind, the overarching goal of this research is to provide a building block that will support policies and organizations that advocate for people with SMI by fighting stigma and increasing affordability and access to housing in any environment. 
Table 1. Descriptive statistics.

\begin{tabular}{|c|c|c|c|c|c|c|c|c|c|}
\hline \multirow{2}{*}{ Measure } & \multirow{2}{*}{$\mathrm{N}$} & \multirow{2}{*}{ Min } & \multirow{2}{*}{ Max } & \multirow{2}{*}{ Mean } & \multirow{2}{*}{ SD } & \multicolumn{2}{|c|}{ Skewness } & \multicolumn{2}{|l|}{ Kurtosis } \\
\hline & & & & & & Statistic & SE & Statistic & SE \\
\hline $\begin{array}{l}\text { Perceived } \\
\text { stigma }\end{array}$ & 292 & 1 & 6 & 3.66 & .99 & -.05 & .14 & -.73 & .28 \\
\hline $\begin{array}{l}\text { Psychological } \\
\text { distress }\end{array}$ & 298 & 1 & 4 & 2.09 & .65 & .33 & .14 & -.36 & .28 \\
\hline $\begin{array}{l}\text { Sense of } \\
\text { Community }\end{array}$ & 300 & 1 & 4 & 2.43 & .74 & .23 & .14 & -.70 & .28 \\
\hline
\end{tabular}


Table 2. Correlations between primary study variables.

\begin{tabular}{lcccc}
\hline & Urbanicity & $\begin{array}{l}\text { Perceived } \\
\text { Stigma }\end{array}$ & $\begin{array}{l}\text { Psychological } \\
\text { distress }\end{array}$ & $\begin{array}{l}\text { Sense of } \\
\text { community }\end{array}$ \\
\hline $\begin{array}{l}\text { Urbanicity } \\
(1=\text { urban; }\end{array}$ & 1 & & \\
$0=$ non-urban $)$ & $-.15^{\star}$ & 1 & & \\
Perceived stigma & $-.14^{*}$ & $.39^{* *}$ & 1 & 1 \\
Psychological distress & $.19^{* *}$ & $-.39^{* *}$ & $-.32^{* *}$ & 1 \\
Sense of community & & & & \\
\hline
\end{tabular}

${ }^{*}$ Correlation is significant at the 0.05 level (2-tailed)

${ }^{* *}$ Correlation is significant at the 0.01 level (2-tailed) 
Table 3. Independent samples t-test: Outcome variables by gender.

\begin{tabular}{|c|c|c|c|c|c|c|c|c|c|c|}
\hline & \multicolumn{3}{|c|}{ Female } & \multicolumn{3}{|c|}{ Male } & \multirow[b]{2}{*}{$\mathrm{t}$} & \multirow[b]{2}{*}{$d f$} & \multicolumn{2}{|c|}{$95 \% \mathrm{Cl}$} \\
\hline & $\overline{\mathrm{M}}$ & SD & $\mathrm{n}$ & $\overline{\mathrm{M}}$ & SD & $\mathrm{n}$ & & & Lower & Upper \\
\hline $\begin{array}{l}\text { Psychological } \\
\text { Distress }\end{array}$ & 2.23 & .65 & 178 & 1.89 & .60 & 118 & $4.50^{\star}$ & 294 & .19 & .49 \\
\hline $\begin{array}{l}\text { Sense of } \\
\text { Community }\end{array}$ & 2.33 & .73 & 179 & 2.58 & .74 & 119 & $-2.87^{*}$ & 296 & -.42 & -.08 \\
\hline
\end{tabular}

*t is significant at the 0.05 level (2-tailed) 
Table 4. Independent samples t-test: Outcome variables by psychiatric diagnosis.

\begin{tabular}{|c|c|c|c|c|c|c|c|c|c|c|}
\hline & \multicolumn{3}{|c|}{$\begin{array}{l}\text { Schizophrenia - } \\
\text { Spectrum (No) }\end{array}$} & \multicolumn{3}{|c|}{$\begin{array}{l}\text { Schizophrenia - } \\
\text { Spectrum (Yes) }\end{array}$} & \multirow[b]{2}{*}{$\mathrm{t}$} & \multirow[b]{2}{*}{$\mathrm{df}$} & \multicolumn{2}{|c|}{$\underline{95 \% \mathrm{Cl}}$} \\
\hline & $M$ & SD & $\mathrm{n}$ & $M$ & SD & $\mathrm{n}$ & & & Lower & Upper \\
\hline $\begin{array}{l}\text { Psychological } \\
\text { Distress }\end{array}$ & 2.16 & .67 & 172 & 2.00 & .62 & 126 & $2.11^{*}$ & 296 & .01 & .31 \\
\hline $\begin{array}{l}\text { Sense of } \\
\text { Community }\end{array}$ & 2.34 & .71 & 172 & 2.56 & .76 & 128 & $-2.64^{*}$ & 298 & -.40 & -.06 \\
\hline
\end{tabular}

${ }^{*} t$ is significant at the 0.05 level (2-tailed) 
Table 5. Moderated regression 1 results (outcome: psychological distress).

\begin{tabular}{lcccccc}
\hline & B & SE & $t$ & $p$ & \multicolumn{2}{c}{$95 \% \mathrm{Cl}$} \\
\hline Gender & -.20 & .08 & -2.58 & .01 & -.35, & -.05 \\
Psychiatric diagnosis & -.07 & .07 & -.91 & .36 & -.21, & .08 \\
Perceived stigma & .23 & .04 & 5.85 & $<.001$ & .15, & .29 \\
Urbanicity & -.09 & .08 & -1.12 & .27 & -.24, & .07 \\
Perceived stigma*urbanicity & -.06 & .08 & -.73 & .47 & -.21, & .10 \\
\hline
\end{tabular}


Table 6. Moderated regression 2 results (outcome: sense of community).

\begin{tabular}{lcccccc}
\hline & B & SE & $t$ & $p$ & \multicolumn{2}{c}{$95 \% \mathrm{Cl}$} \\
\hline Gender & .07 & .09 & .82 & .41 & -.10 & .24 \\
Psychiatric diagnosis & .16 & .08 & 1.91 & .06 & -.01 & .32 \\
Perceived stigma & -.26 & .04 & -6.17 & $<.001$ & -.34 & -.18 \\
Urbanicity & .19 & .09 & 2.14 & .03 & .02 & .36 \\
Perceived stigma*urbanicity & .04 & .09 & .41 & .68 & -.14 & .21 \\
\hline
\end{tabular}


Figure 1. Proposed model of the relationship between perceived stigma and psychological distress as moderated by urbanicity.

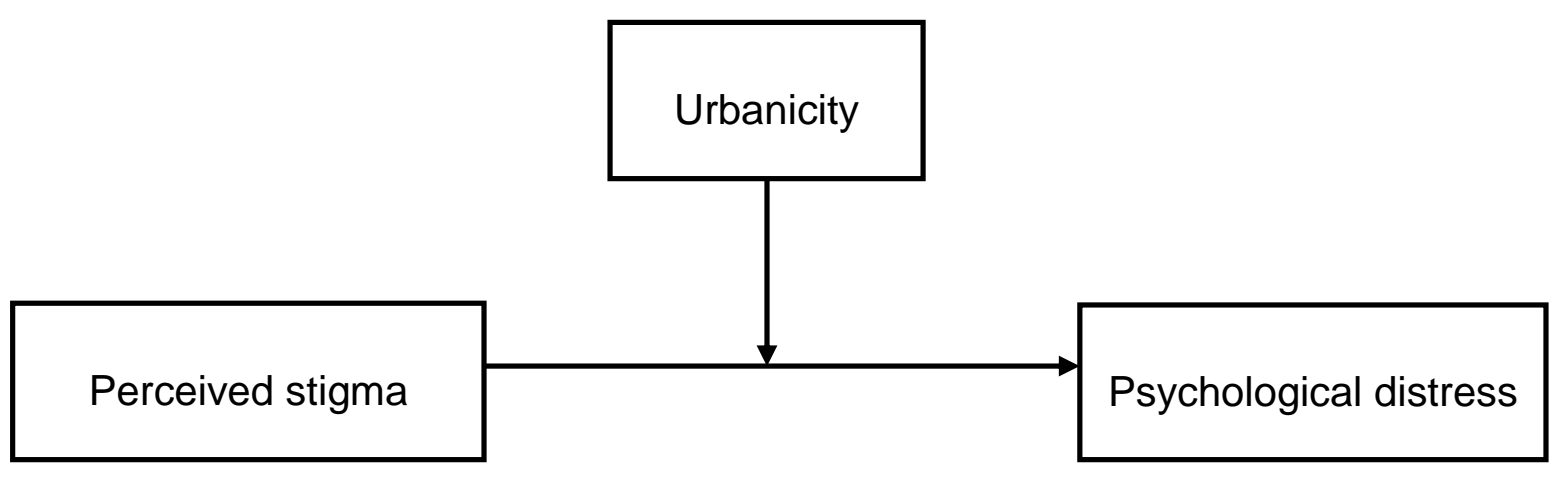


Figure 2. Proposed model of the relationship between perceived stigma and sense of community as moderated by urbanicity.

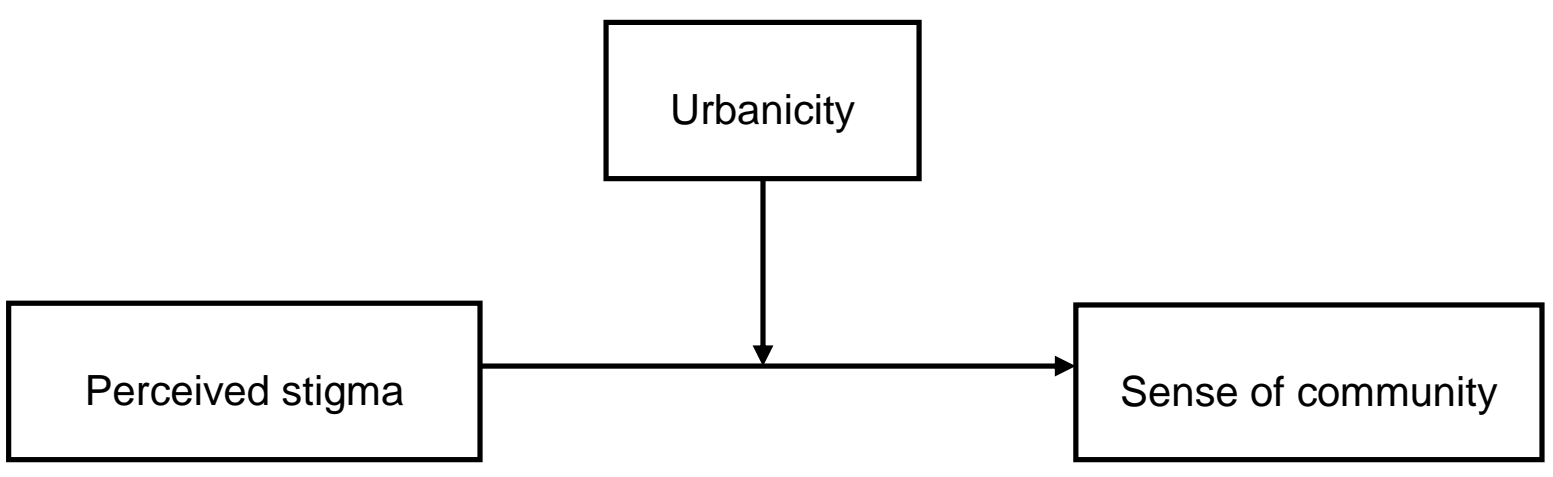


Figure 3. Recruitment diagram.

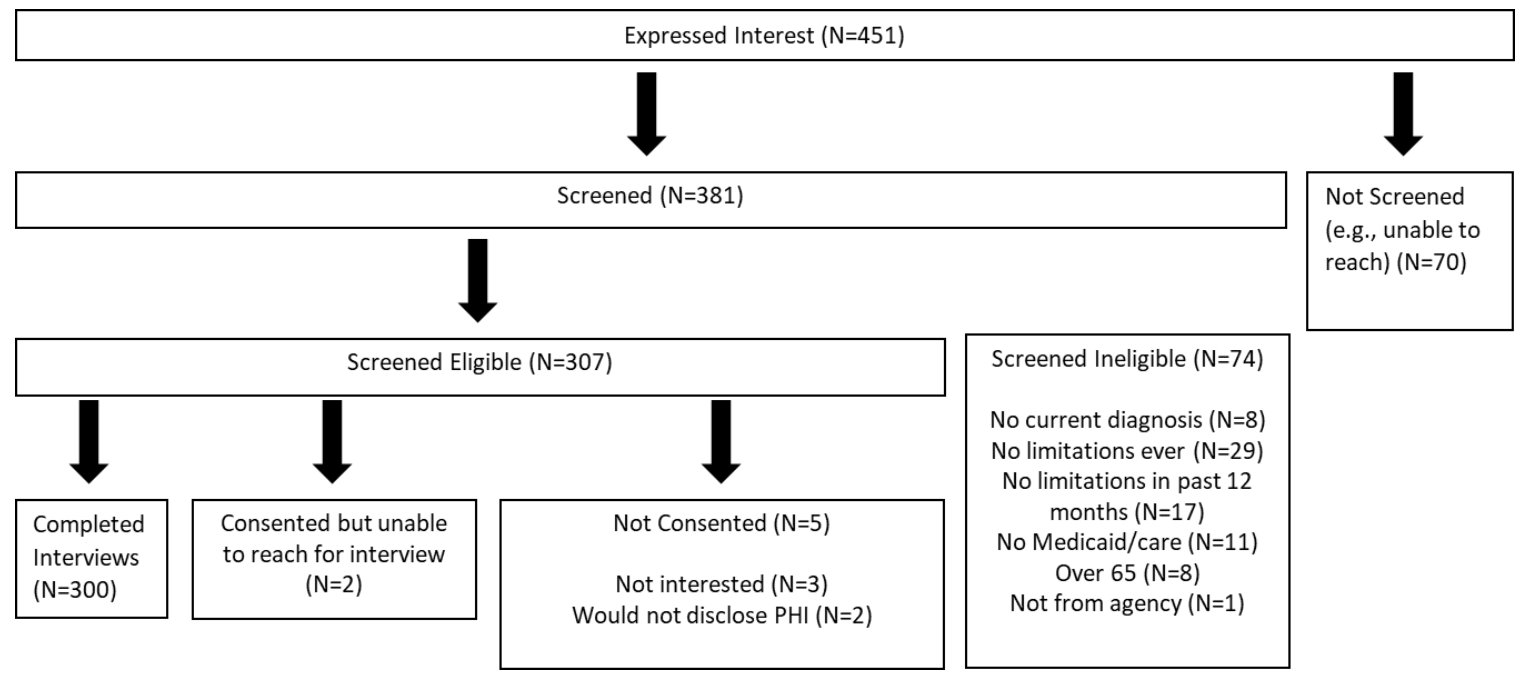


Figure 4. Geographic Location of study participants by levels of urbanicity.

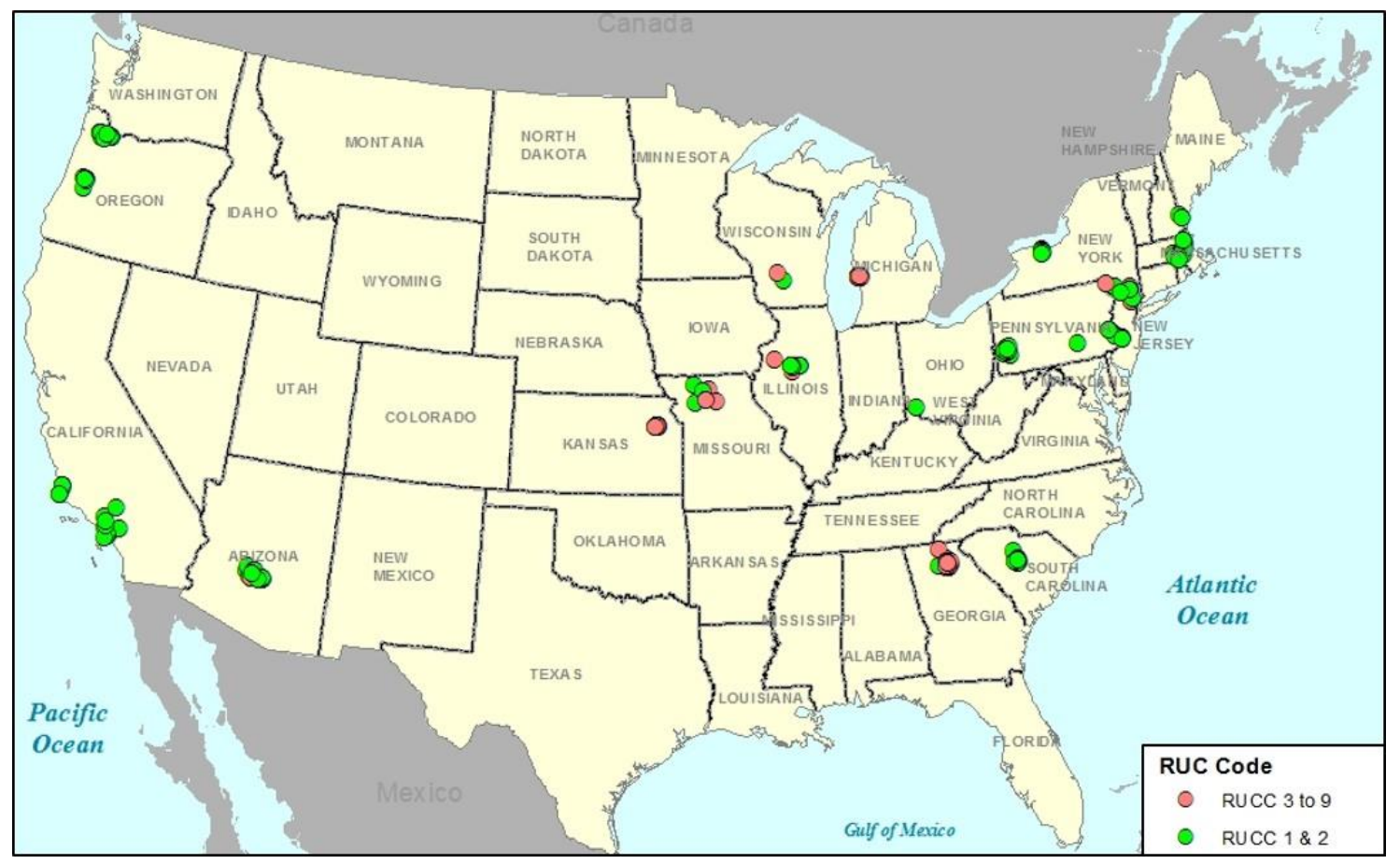


Figure 5. Moderated regression results for psychological distress outcome.

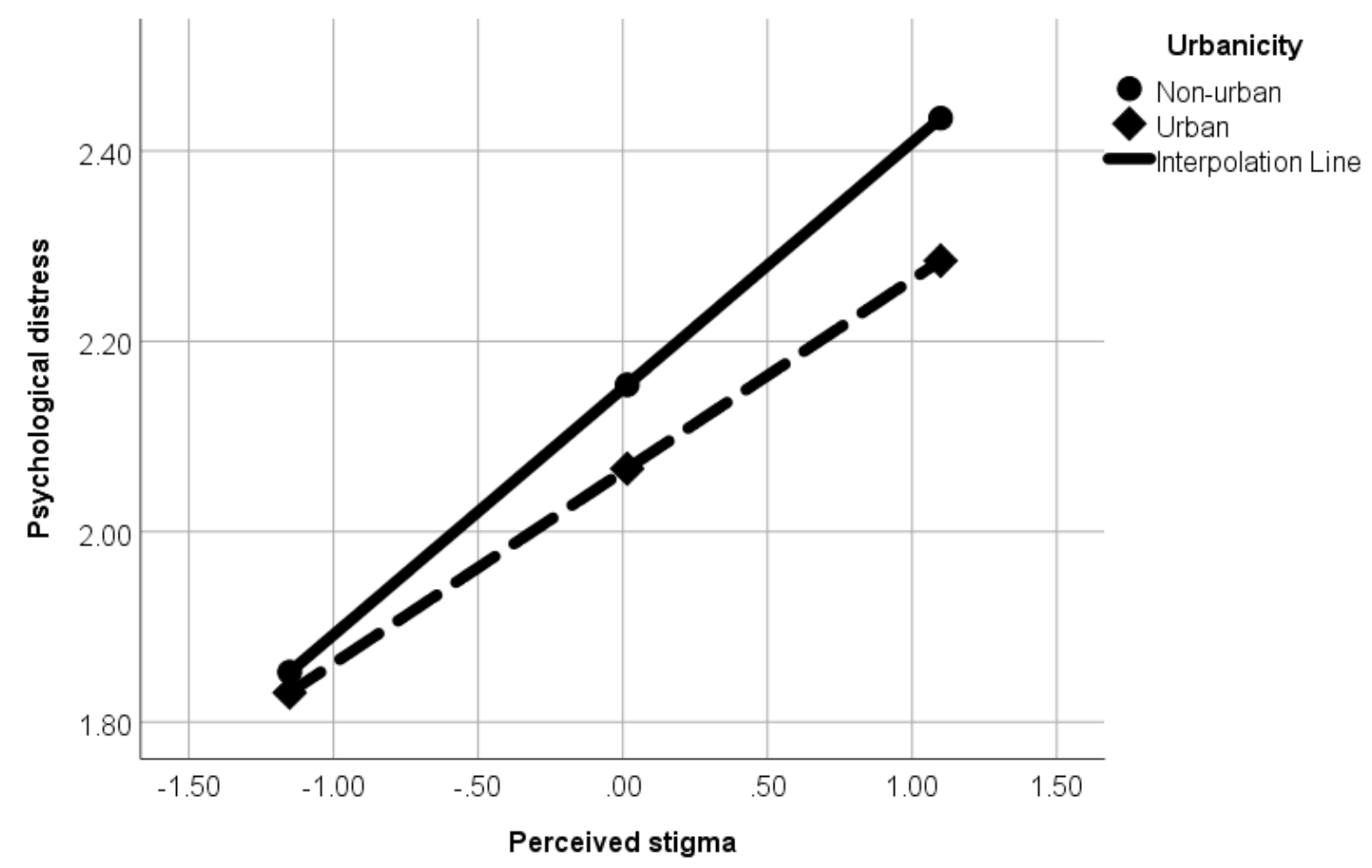

Note: Perceived stigma was centered prior to analysis. Psychological distress range was 1-4. 
Figure 6. Moderated regression results for sense of community outcome.

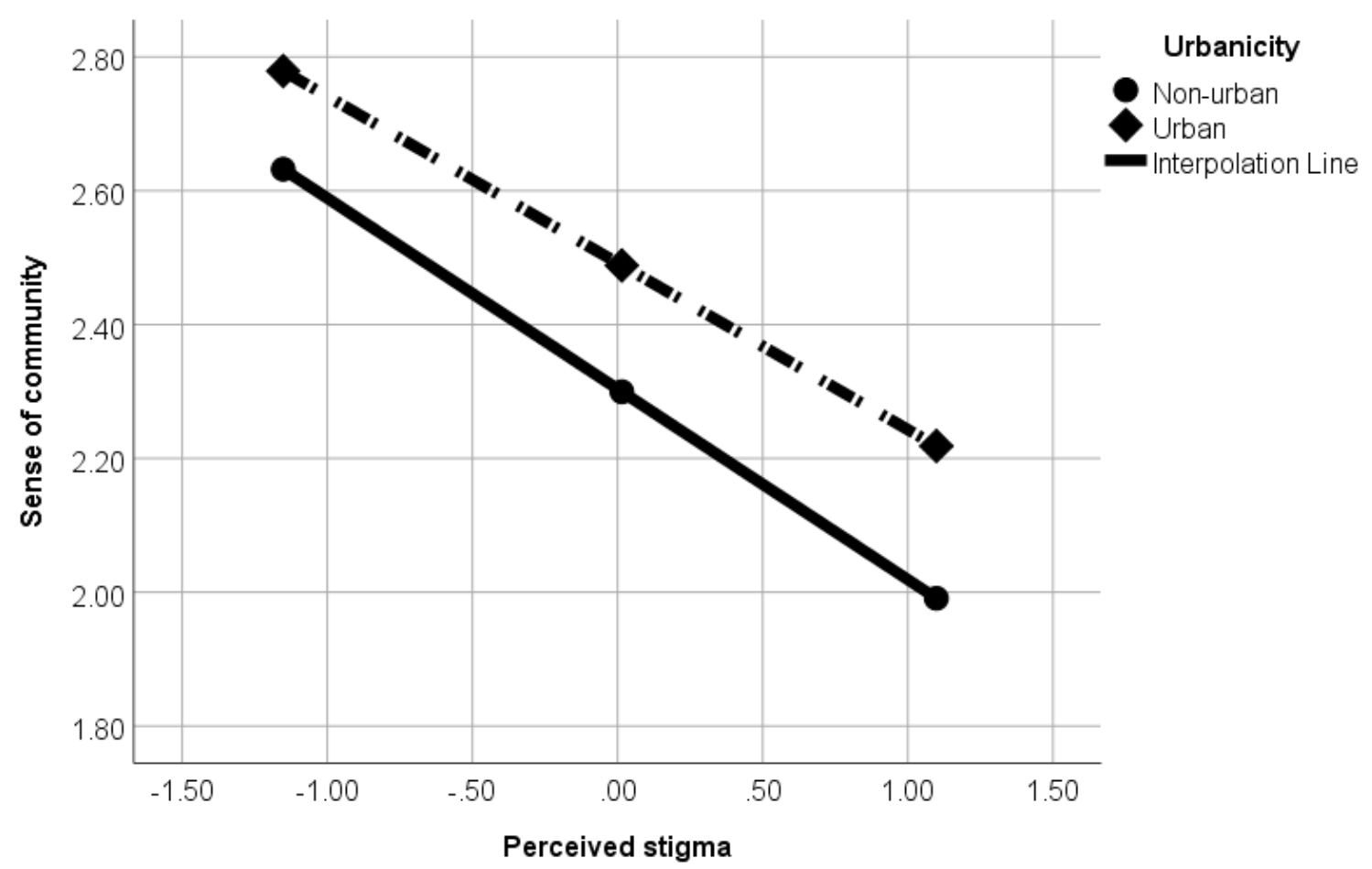

Note: Perceived stigma was centered prior to analysis. Sense of community range was 1-4. 


\section{References}

Abdallah, C., Cohen, C. I., Sanchez-Almira, M., Reyes, P., \& Ramirez, P. (2009). Community integration and associated factors among older adults with schizophrenia. Psychiatric Services, 60(12).

Abdullah, T., \& Brown, T. L. (2011). Mental illness stigma and ethnocultural beliefs, values, and norms: An integrative review. Clinical Psychology Review, 31(6), 934-948. https://doi.org/10.1016/j.cpr.2011.05.003

Ali, A., King, M., Strydom, A., \& Hassiotis, A. (2015). Self-reported stigma and symptoms of anxiety and depression in people with intellectual disabilities: Findings from a cross sectional study in England. Journal of Affective Disorders, 187, 224-231. https://doi.org/10.1016/j.jad.2015.07.046

Allport, G. W. (1954). The nature of prejudice. Cambridge, Mass: AddisonWesley Pub. Co.

Angelo, F. N., McDonell, M. G., Lewin, M. R., Srebnik, D., Lowe, J., Roll, J., \& Ries, R. (2013). Predictors of stimulant abuse treatment outcomes in severely mentally ill outpatients. Drug and Alcohol Dependence, 131(1-2), 162-165. https://doi.org/10.1016/J.DRUGALCDEP.2012.11.017

Angermeyer, M. C., \& Dietrich, S. (2006). Public beliefs about and attitudes towards people with mental illness: a review of population studies. Acta Psychiatrica Scandinavica, 113(3), 163-179. https://doi.org/10.1111/j.16000447.2005.00699.x

Atkinson, M., Zibin, S., \& Chuang, H. (1997). Characterizing quality of life among patients with chronic mental illness: a critical examination of the self-report methodology. American Journal of Psychiatry, 154(1), 99-105. https://doi.org/10.1176/ajp.154.1.99

Aubry, T., \& Myner, J. (1996). Community integration and quality of life: A comparison of persons with psychiatric disabilities in housing programs and community residents who are neighbours. Canadian Journal of Community Mental Health, 15(1), 5-20. https://doi.org/10.7870/cjcmh-1996-0001

Baron, R. M., \& Kenny, D. A. (1986). The moderator-mediator variable distinction in social psychological research: conceptual, strategic, and statistical considerations. Journal of Personality and Social Psychology, 51(6), 11731182.

Brenes, G. A., Danhauer, S. C., Lyles, M. F., Hogan, P. E., \& Miller, M. E. (2015). Barriers to mental health treatment in rural older adults. The American Journal of Geriatric Psychiatry: Official Journal of the American Association for Geriatric Psychiatry, 23(11), 1172-1178. https://doi.org/10.1016/j.jagp.2015.06.002 
Buchanan, L., Fessenden, F., Parlapiano, A., Yourish, K., Pearce, A., Wallace, T., ... Williams, J. (2016). How Trump Reshaped the Election Map.

Retrieved from

http://www.nytimes.com/interactive/2016/11/08/us/elections/how-trump-

pushed-the-election-map-to-the-right.html?ref=politics

Cadinu, M., \& Reggiori, C. (2002). Discrimination of a low-status outgroup: the role of ingroup threat. European Journal of Social Psychology, 32(4), 501515. https://doi.org/10.1002/ejsp.105

Chan, K. K. S., \& Mak, W. W. S. (2014). The mediating role of self-stigma and unmet needs on the recovery of people with schizophrenia living in the community. Quality of Life Research. https://doi.org/10.1007/s11136-0140695-7

Chavis, D. M., Lee, K. S., \& Acosta, J. D. (2008). The sense of community (SCI) revised: The reliability and validity of the SCl-2. In 2 nd international community psychology conference, Lisboa, Portugal.

Chavis, D. M., \& Wandersman, A. (1990). Sense of community in the urban environment: A catalyst for participation and community development. American Journal of Community Psychology, 18(1), 55-81. https://doi.org/10.1007/BF00922689

Coblentz, P., Leickly, E., Chwastiak, L., Cristofalo, M. A., Ries, R. K., \& McDonell, M. G. (2015). Schizophrenia and metabolic syndrome in rural communities: Understanding barriers and improving care. Journal of Rural Mental Health, 39(1), 34-45. https://doi.org/10.1037/rmh0000025

Cohen, J., Cohen, P., West, S., \& Aiken, L. (2003). Applied Multiple Regression/Correlation Analysis for the Behavioral Sciences. Lawrence Erlbaum Associates.

Cook, B. L., Wayne, G. F., Kafali, E. N., Liu, Z., Shu, C., \& Flores, M. (2014). Trends in smoking among adults with mental illness and association between mental health treatment and smoking cessation. JAMA, 311(2), 172. https://doi.org/10.1001/jama.2013.284985

Corrigan, P. W. (2006). Impact of consumer-operated services on empowerment and recovery of people with psychiatric disabilities. Psychiatric Services, 57(10), 1493-1496. https://doi.org/10.1176/ps.2006.57.10.1493

Corrigan, P. W., Sokol, K. A., \& Rüsch, N. (2013). The impact of self-stigma and mutual help programs on the quality of life of people with serious mental illnesses. Community Mental Health Journal, 49(1), 1-6. https://doi.org/10.1007/s10597-011-9445-2

Crisanti, A. S., Duran, D., Greene, R. N., Reno, J., Luna-Anderson, C., \& 
Altschul, D. B. (2017). A longitudinal analysis of peer-delivered permanent supportive housing: Impact of housing on mental and overall health in an ethnically diverse population. Psychological Services, 14(2), 141-153. https://doi.org/10.1037/ser0000135

Dahly, D. L., \& Adair, L. S. (2007). Quantifying the urban environment: A scale measure of urbanicity outperforms the urban-rural dichotomy. Social Science \& Medicine, 64(7), 1407-1419. https://doi.org/10.1016/j.socscimed.2006.11.019

Davidson, W. B., \& Cotter, P. R. (1991). The relationship between sense of community and subjective well-being: A first look. Journal of Community Psychology, 19(3), 246-253. https://doi.org/10.1002/15206629(199107)19:3<246::AID-JCOP2290190308>3.0.CO;2-L

Davis, B. A., Townley, G., \& Kloos, B. (2013). The roles of clinical and nonclinical dimensions of recovery in promoting community activities for individuals with psychiatric disabilities. Psychiatric Rehabilitation Journal, 36(1), 51-53. https://doi.org/10.1037/h0094749

Dear, M. J., \& Wolch, J. B. (1987). Landscapes of Despair: From Deinstitutionalization to Homelessness. Princeton, NJ: Princeton University Press.

Derogatis, L. R., Lipman, R. S., Rickels, K., Uhlenhuth, E. H., \& Covi, L. (1974). The Hopkins Symptom Checklist (HSCL): A self-report symptom inventory. Behavioral Science, 19(1), 1-15. https://doi.org/10.1002/bs.3830190102

Dhingra, S. S., Strine, T. W., Holt, J. B., Berry, J. T., \& Mokdad, A. H. (2009). Rural-urban variations in psychological distress: findings from the Behavioral Risk Factor Surveillance System, 2007. International Journal of Public Health, 54(S1), 16-22. https://doi.org/10.1007/s00038-009-0002-5

Dovidio, J. F., Love, A., Schellhaas, F. M. H., \& Hewstone, M. (2017). Reducing intergroup bias through intergroup contact: Twenty years of progress and future directions. Group Processes \& Intergroup Relations, 136843021771205. https://doi.org/10.1177/1368430217712052

Duncan, C. M., \& Tickamyer, A. R. (1988). Poverty and opportunity structure in rural America. The American Sociologist, 19(3), 243-259. https://doi.org/10.1007/BF02691983

Ellis, A. R., Konrad, T. R., Thomas, K. C., \& Morrissey, J. P. (2009). County-level estimates of mental health professional supply in the United States. Psychiatric Services, 60(10), 1315-1322. https://doi.org/10.1176/ps.2009.60.10.1315

Etopio, A. L., Devereux, P., \& Crowder, M. (2018). Perceived campus safety as a 
mediator of the link between gender and mental health in a national U.S. college sample. Women \& Health, 1-15.

https://doi.org/10.1080/03630242.2018.1549646

Ferraro, K. F., \& Nuriddin, T. A. (2018). Psychological distress and mortality: Are women more vulnerable? American Sociological Association, 47(3), 227241.

Fischer, C. S. (1975). Toward a subcultural theory of urbanism. American Journal of Sociology, 80(6), 1319-1341.

Forchuk, C., Nelson, G., \& Brent Hall, G. (2006). "It's important to be proud of the place you live in": Housing problems and preferences of psychiatric survivors. Perspectives in Psychiatric Care, 42(1).

Freedman, R. I., \& Moran, A. (1984). Wanderers in a promised land: The chronically mentally ill and deinstitutionalization. Medical Care, 22(12), 1-68.

Furnham, A., Annis, J., \& Cleridou, K. (2014). Gender differences in the mental health literacy of young people. International Journal of Adolescent Medicine and Health, 26(2), 283-292. https://doi.org/10.1515/ijamh-2013-0301

Goldberg, R. W., Seybolt, D. C., \& Lehman, A. (2002). Reliable self-report of health service use by individuals with serious mental illness. Psychiatric Services, 53(7), 879-881. https://doi.org/10.1176/appi.ps.53.7.879

Gong, Y., Palmer, S., Gallacher, J., Marsden, T., \& Fone, D. (2016). A systematic review of the relationship between objective measurements of the urban environment and psychological distress. Environment International, 96, 4857. https://doi.org/10.1016/J.ENVINT.2016.08.019

Gonzales, L., Chan, G., \& Yanos, P. T. (2017). Individual and neighborhood predictors of mental illness stigma in New York state. Stigma and Health, 2(3), 175-181. https://doi.org/10.1037/sah0000043

Gonzales, L., Yanos, P. T., Stefancic, A., \& Alexander, M. J. (2018). The role of neighborhood factors and community stigma in predicting community participation among persons with psychiatric disabilities. Psychiatric Services, 69, 76-83. https://doi.org/10.1176/appi.ps.201700165

González-Torres, M. A., Oraa, R., Arístegui, M., Fernández-Rivas, A., \& Guimon, J. (2007). Stigma and discrimination towards people with schizophrenia and their family members. Social Psychiatry and Psychiatric Epidemiology, 42(1), 14-23. https://doi.org/10.1007/s00127-006-0126-3

Gulcur, L., Tsemberis, S., Stefancic, A., \& Ronni Greenwood, M. M. (2007). Community integration of adults with psychiatric disabilities and histories of homelessness. Community Mental Health Journal, 43(3). 
https://doi.org/10.1007/s10597-006-9073-4

Hagman, B. T., Delnevo, C. D., Hrywna, M., \& Williams, J. M. (2008). Tobacco use among those with serious psychological distress: Results from the National Survey of Drug Use and Health, 2002. Addictive Behaviors2, 33(4), 582-592. https://doi.org/10.1016/j.addbeh.2007.11.007

Hatzenbuehler, M. L. (2016). Structural stigma: Research evidence and implications for psychological science. American Psychologist, 71(8), 742751. https://doi.org/10.1037/amp0000068

Hayes, A. F., \& Little, T. D. (2018). Introduction to mediation, moderation, and conditional process analysis: A regression-based approach (2nd ed.). New York, NY: The Guilford Press.

Hefner, J., \& Eisenberg, D. (2009). Social support and mental health among college students. American Journal of Orthopsychiatry, 79(4), 491-499. https://doi.org/10.1037/a0016918

Herek, G. M., Saha, S., \& Burack, J. (2013). Stigma and psychological distress in people with HIV/AIDS. Basic and Applied Social Psychology, 35(1), 41-54. https://doi.org/10.1080/01973533.2012.746606

Holahan, C. J., \& Moos, R. H. (1981). Social support and psychological distress: A longitudinal analysis. Journal of Abnormal Psychology, 90(4), 365-370. https://doi.org/10.1037/0021-843X.90.4.365

Holman, D. (2015). Exploring the relationship between social class, mental illness stigma and mental health literacy using British national survey data. Health: An Interdisciplinary Journal for the Social Study of Health, Illness and Medicine, 19(4), 413-429. https://doi.org/10.1177/1363459314554316

Housing Assistance Council. (2012). Race \& Ethnicity in Rural America. Washington, DC. Retrieved from http://www.ruralhome.org/storage/research_notes/rrn-race-and-ethnicityweb.pdf

Jacobs, J. (1961). The Death and Life of Great American Cities. (V. Books, Ed.). New York, NY: Random House, Inc.

Janssen, E. M., Mcginty, E. E., Azrin, S. T., Juliano-Bult, D., Daumit, G. L., \& Hosp, G. (2015). Review of the evidence: Prevalence of medical conditions in the United States population with Serious Mental Illness. Gen Hosp Psychiatry, 37(3), 199-222. https://doi.org/10.1016/j.genhosppsych.2015.03.004

Jorm, A. F. (2000). Mental health literacy: Public knowledge and beliefs about mental disorders. The British Journal of Psychiatry, 177(5), 396-401. 
Kashyap, S., Hooke, G. R., \& Page, A. C. (2015). Identifying risk of deliberate self-harm through longitudinal monitoring of psychological distress in an inpatient psychiatric population. BMC Psychiatry, 15(1), 81. https://doi.org/10.1186/s12888-015-0464-3

Katon, W., \& Ciechanowski, P. (2002). Impact of major depression on chronic medical illness. Journal of Psychosomatic Research, 53, 859-863.

Katz, B., \& Lang, R. E. (2003). Redefining Urban and Suburban America: Evidence from Census 2000. (B. Katz \& R. E. Lang, Eds.). Washington, DC: Brookings Institution Press.

Kessler, R. C., Berglund, P. A., Bruce, M. L., Koch, J. R., Laska, E. M., Leaf, P., ... Wang, P. S. (2001). The prevalence and correlates of untreated serious mental illness. Health Services Research, 36(6).

Kline, R. (2011). Principles and practice of structural equation modeling. New York: Guilford Press.

Kloos, B., \& Townley, G. (2011). Investigating the relationship between neighborhood experiences and psychiatric distress for individuals with serious mental illness. Administration and Policy in Mental Health and Mental Health Services Research, 38(2), 105-116. https://doi.org/10.1007/s10488-010-0307-y

Krabbendam, L., \& Van Os, J. (2005). Schizophrenia and urbanicity: A major environmental influence - Conditional on genetic risk. Schizophrenia Bulletin, 31(4), 795-799. https://doi.org/10.1093/schbul/sbi060

Kriegel, L. S., Townley, G., Brusilovskiy, E., \& Salzer, M. S. (2019). Neighbors as distal support for individuals with serious mental illnesses. American Journal of Orthopsychiatry. https://doi.org/10.1037/ort0000403

Lederbogen, F., Kirsch, P., Haddad, L., Streit, F., Tost, H., Schuch, P., ... MeyerLindenberg, A. (2011). City living and urban upbringing affect neural social stress processing in humans. Nature, 474(7352), 498-501. https://doi.org/10.1038/nature10190

Lewis, G., \& David, A. (1992). Schizophrenia and city life. Lancet, 340(8812), 137.

Link, B. G. (1987). Understanding labeling effects in the area of mental disorders: An assessment of the effects of expectations of rejection. American Sociological Review, 52(1), 96-112.

Link, B. G., Cullen, F. T., Struening, E., Shrout, P. E., Dohrenwend, P., Link, B. G., ... Shrout, P. E. (1989). A Modified Labeling Theory approach to mental disorders: An empirical assessment. American Sociological Association, 
54(3), 400-423.

Magliano, L., De Rosa, C., Fiorillo, A., Malangone, C., Maj, M., \& Group, and the N. M. H. P. W. (2004). Perception of patients' unpredictability and beliefs on the causes and consequences of schizophrenia. Social Psychiatry and Psychiatric Epidemiology, 39(5), 410-416. https://doi.org/10.1007/s00127004-0764-2

Mak, W. W. S., Cheung, R. Y. M., \& Law, L. S. C. (2009). Sense of community in Hong Kong: Relations with community-level characteristics and residents' well-being. American Journal of Community Psychology, 44(1-2), 80-92. https://doi.org/10.1007/s10464-009-9242-z

Marré, A. (2017). Rural Education At A Glance, 2017 Edition, (April). https://doi.org/98

McDonel, E. C., Bond, G. R., Salyers, M., Fekete, D., Chen, A., McGrew, J. H., \& Miller, L. (1997). Implementing Assertive Community Treatment programs in rural settings. Administration and Policy in Mental Health, 25(2), 153-173. https://doi.org/10.1023/A:1022286921362

McMahon, F. J. (2014). Prediction of treatment outcomes in psychiatry--where do we stand? Dialogues in Clinical Neuroscience, 16(4), 455-464.

McMillan, D. W., \& Chavis, D. M. (1986). Sense of community: A definition and theory. Journal of Community Psychology, 14(1), 6-23. https://doi.org/10.1002/1520-6629(198601)14:1<6::AIDJCOP2290140103>3.0.CO;2-I

Metraux, S., Brusilovskiy, E., Prvu-Bettger, J. A., Irene Wong, Y.-L., \& Salzer, M. S. (2012). Geographic access to and availability of community resources for persons diagnosed with severe mental illness in Philadelphia, USA. Health \& Place, 18(3), 621-629. https://doi.org/10.1016/j.healthplace.2011.12.011

Mortensen, P. B. (2000). Urban-rural differences in the risk for schizophrenia. International Journal of Mental Health, 29(3), 101-110. https://doi.org/10.1080/00207411.2000.11449499

Newman, K., \& Wyly, E. K. (2006). The right to stay put, revisited: Gentrification and resistance to displacement in New York City. Urban Studies, 43(1), $23-$ 57. https://doi.org/10.1080/00420980500388710

Newsom, J. T., Prigerson, H. G., Schulz, R., \& Reynolds, C. F. (2003). Investigating moderator hypotheses in aging research: Statistical, methodological, and conceptual difficulties with comparing separate regressions. The International Journal of Aging and Human Development, 57(2), 119-150. https://doi.org/10.2190/13LV-B3MM-PEWJ-3P3W 
Ojike, N., Sowers, J. R., Seixas, A., Ravenell, J., Rodriguez-Figueroa, G., Awadallah, M., ... McFarlane, S. I. (2016). Psychological distress and hypertension: results from the national health interview survey for 20042013. CardioRenal Medicine, 6(3), 198-208. https://doi.org/10.1159/000443933

Ozawa, C. P. (Ed.). (2004). The Portland Edge: Challenges And Successes In Growing Communities. Washington, DC: Island Press.

Parr, H., Philo, C., \& Burns, N. (2004). Social geographies of rural mental health: Experiencing inclusions and exclusions. Transactions of the Institute of British Geographers, 29(4), 401-419. https://doi.org/10.1111/j.00202754.2004.00138.x

Pedersen, C. B. (2001). Evidence of a dose-response relationship between urbanicity during upbringing and schizophrenia risk. Archives of General Psychiatry, 58(11), 1039-1046. https://doi.org/10.1001/archpsyc.58.11.1039

Peen, J., Schoevers, R. A., Beekman, A. T., \& Dekker, J. (2010). The current status of urban-rural differences in psychiatric disorders. Acta Psychiatrica Scandinavica, 121(2), 84-93. https://doi.org/10.1111/j.16000447.2009.01438.x

Pinfold, V., Byrne, P., \& Toulmin, H. (2005). Challenging stigma and discrimination in communities: A focus group study identifying UK mental health service users' main campaign priorities. International Journal of Social Psychiatry, 51(2), 128-138. https://doi.org/10.1177/0020764005056760

Pini, S., Cassano, G. B., Liliana Dell, Frcp., \& Amador, X. F. (2001). Insight into illess in schizophrenia, schizoaffective disorder, and mood disorders with psychotic features. American Journal of Psychiatry, 158(158), 122-125.

Pratt, L. A. (2012). Characteristics of adults with Serious Mental Illness in the United States household population in 2007. Psychiatric Services, 63(10), 1042-1046. https://doi.org/10.1176/appi.ps.201100442

Pretty, G. M. H., Conroy, C., Dugay, J., Fowler, K., \& Williams, D. (1996). Sense of community and its relevance to adolescents of all ages. Journal of Community Psychology, 24(4), 365-379.

Prince, P. N., \& Prince, C. R. (2002). Perceived stigma and community integration among clients of assertive community treatment. Psychiatric Rehabilitation Journal, 25(4), 323-331. https://doi.org/10.1037/h0095005

Quinn, D. M., \& Chaudoir, S. R. (2009). Living with a concealable stigmatized identity: The impact of anticipated stigma, centrality, salience, and cultural stigma on psychological distress and health. Journal of Personality and Social Psychology, 97(4), 634-651. https://doi.org/10.1037/a0015815 
Quinn, D. M., Williams, M. K., Quintana, F., Gaskins, J. L., Overstreet, N. M., Pishori, A., ... Chaudoir, S. R. (2014). Examining effects of anticipated stigma, centrality, salience, internalization, and outness on psychological distress for people with concealable stigmatized identities. PLOS ONE, 9(5). https://doi.org/10.1371/journal.pone.0096977

Reese, E., Deverteuil, G., \& Thach, L. (2010). 'Weak-center' gentrification and the contradictions of containment: Deconcentrating poverty in downtown Los Angeles. International Journal of Urban and Regional Research, 34(2), 310327. https://doi.org/10.1111/j.1468-2427.2010.00900.x

Robey, K. L. (1994). Group home residents' identities as patients and as community members. Psychiatric Services, 45(1), 58-62. https://doi.org/10.1176/ps.45.1.58

Romans, S., Cohen, M., \& Forte, T. (2011). Rates of depression and anxiety in urban and rural Canada. Social Psychiatry and Psychiatric Epidemiology, 46(7), 567-575. https://doi.org/10.1007/s00127-010-0222-2

Rosenfield, S. (1997). Labeling mental illness: The effects of received services and perceived stigma on life satisfaction. American Sociological Review, 62(4), 660-672. Retrieved from https://www-jstororg.proxy.lib.pdx.edu/stable/pdf/2657432.pdf

Rost, K., Smith, G. R., \& Taylor, J. L. (1993). Rural-urban differences in stigma and the use of care for depressive disorders. The Journal of Rural Health, 9(1), 57-62.

Russ, T. C., Stamatakis, E., Hamer, M., Starr, J. M., Kivimäki, M., Batty, G. D., ... Batty, D. (2018). Association between psychological distress and mortality: Individual participant pooled analysis of 10 prospective cohort studies. British Medical Journal, 345(7871), 14-15. https://doi.org/10.1136/bmj.e4933

Russell, R., Guerry, A. D., Balvanera, P., Gould, R. K., Basurto, X., Chan, K. M. A., ... Tam, J. (2013). Humans and nature: how knowing and experiencing nature affect well-being. Annual Review of Environment and Resources, (38), 473-502. https://doi.org/10.1146/annurev-environ-012312-110838

Salyers, M. P., Bosworth, H. B., Swanson, J. W., Lamb-Pagone, J., \& Osher, F. C. (2000). Reliability and validity of the SF-12 health survey among people with severe mental illness. Medical Care, 38(11), 1141-1150. Retrieved from https://www.jstor.org/stable/pdf/3767812.pdf

SAMHSA. (2017). Key substance use and mental health indicators in the United States: Results from the 2016 National Survey on Drug Use and Health. Retrieved from https://www.samhsa.gov/data/

Sandanger, I., Moum, T., Ingebrigtsen, G., Dalgard, O. S., Sørensen, T., \& 
Bruusgaard, D. (1998). Concordance between symptom screening and diagnostic procedure: the Hopkins Symptom Checklist-25 and the Composite International Diagnostic Interview I. Social Psychiatry and Psychiatric Epidemiology, 33(7), 345-354. https://doi.org/10.1007/s001270050064

Sarason, S. B. (1974). The psychological sense of community: Prospects for a community psychology. Jossey-Bass San Francisco.

Schibalski, J. V., Müller, M., Ajdacic-Gross, V., Vetter, S., Rodgers, S., Oexle, N., ... Rüsch, N. (2017). Stigma-related stress, shame and avoidant coping reactions among members of the general population with elevated symptom levels. Comprehensive Psychiatry, 74, 224-230. https://doi.org/10.1016/j.comppsych.2017.02.001

Schulze, B., \& Angermeyer, M. C. (2003). Subjective experiences of stigma. A focus group study of schizophrenic patients, their relatives and mental health professionals. Social Science \& Medicine, 56, 299-312.

Shih, M., Simon, P. A., Quality, S., May, N., Shih, M., \& Simon, P. A. (2018). Health-related quality of life among adults with serious psychological distress and chronic medical conditions. Quality of Life Research, 17(4), 521-528. https://doi.org/10.1007/sl

Silverman, C. J., \& Segal, S. P. (1994). Who belongs? An analysis of ex-mental patients' subjective involvement in the neighborhood. Adult Residential Care Journal. Retrieved from http://psycnet.apa.org.proxy.lib.pdx.edu/record/1995-22834-001

Sommers, I. (1989). Geographic location and mental health services utilization among the chronically mentally ill. Community Mental Health Journal, 25(2), 132-144.

Sonn, C. C., Bishop, B. J., \& Drew, N. M. (1999). Sense of community: Issues and considerations from a cross-cultural perspective. Community, Work \& Family, 2(2), 205-218.

Stewart, H., Jameson, J. P., \& Curtin, L. (2015). The relationship between stigma and self-reported willingness to use mental health services among rural and urban older adults. Psychological Services, 12(2), 141-148. https://doi.org/10.1037/a0038651

Stuart, H., \& Arboleda-Florez, J. (2001). Community attitudes toward people with schizophrenia. Canadian Journal of Psychiatry, 46, 245-252.

Subandi, M. A. (2015). Bangkit: The processes of recovery from first episode psychosis in Java. Culture, Medicine and Psychiatry. https://doi.org/10.1007/s11013-015-9427-x 
Tang, F., Byrne, M., \& Qin, P. (2018). Psychological distress and risk for suicidal behavior among university students in contemporary China.

https://doi.org/10.1016/j.jad.2017.12.005

Thomas, K. C., Ellis, A. R., Konrad, T. R., Holzer, C. E., \& Morrissey, J. P. (2009). County-level estimates of mental health professional shortage in the United States. Psychiatric Services, 60(10), 1323-1328.

https://doi.org/10.1176/ps.2009.60.10.1323

Townley, G. (2018). Spatial and social factors associated with community integration of individuals with psychiatric disabilities residing in supported and non-supported housing. In M. L \& R. P (Eds.), The Handbook of Mental Health and Space: Community and Clinical Applications (pp. 180-199). New York, NY: Rutledge.

Townley, G., Brusilovskiy, E., \& Salzer, M. S. (2017). Urban and non-urban differences in community living and participation among individuals with serious mental illnesses. Social Science \& Medicine, 177, 223-230. https://doi.org/10.1016/J.SOCSCIMED.2017.01.058

Townley, G., \& Kloos, B. (2011). Examining the psychological sense of community for individuals with serious mental illness residing in supported housing environments. Community Mental Health Journal, 47(4), 436-446. https://doi.org/10.1007/s10597-010-9338-9

Townley, G., Kloos, B., \& Wright, P. A. (2009). Understanding the experience of place: Expanding methods to conceptualize and measure community integration of persons with serious mental illness. Health \& Place, 15(2), 520-531. https://doi.org/10.1016/J.HEALTHPLACE.2008.08.011

United States Department of Agriculture Economic Research Service. (2017). Rural education at a glance, 2017 edition.

US Census Bureau. (2010). 2010 Census Urban and Rural Classification and Urban Area Criteria. Retrieved from https://www-censusgov.proxy.lib.pdx.edu/geo/reference/ua/urban-rural-2010.html

USDA Economic Research Service. (2013). Rural-Urban continuum codes. Retrieved from https://www.ers.usda.gov/data-products/rural-urbancontinuum-codes.aspx

van Os, J., Kenis, G., \& Rutten, B. P. F. (2010). The environment and schizophrenia. Nature, 468(7321), 203-212. https://doi.org/10.1038/nature09563

Veijola, J., Jokelainen, J., Läksy, K., Kantojärvi, L., Kokkonen, P., Järvelin, M., \& Joukamaa, M. (2003). The Hopkins Symptom Checklist-25 in screening DSM-III-R axis-I disorders. Nordic Journal of Psychiatry, 57(2), 119-123. 
https://doi.org/10.1080/08039480310000941

Wahl, O. F., \& Harman, C. R. (1989). Family views of stigma. Schizophrenia Bulletin, 15(1), 131-139. https://doi.org/10.1093/schbul/15.1.131

Warren, C. A. B. (1981). New forms of social control: The myth of deinstitutionalization. American Behavioral Scientist, 24(6), 724-740. Retrieved from https://journals-sagepubcom.proxy.lib.pdx.edu/doi/pdf/10.1177/000276428102400601

Watson, A. C., Corrigan, P., Larson, J. E., \& Sells, M. (2007). Self-stigma in people with mental illness. Schizophrenia Bulletin, 33(6), 1312-1318. https://doi.org/10.1093/schbul/sbl076

Watson, A. C., Corrigan, P. W., \& Angell, B. (2005). What motivates public support for legally mandates mental health treatment? Social Work Research, 29(2), 87-94.

Weisz, C., \& Quinn, D. M. (2017). Stigmatized identities, psychological distress, and physical health: Intersections of homelessness and race. Stigma and Health, 3(3), 229-240. https://doi.org/10.1037/sah0000093

Wirth, L. (1938). Urbanism as a way of life. American Journal of Sociology, 44(1), $1-24$.

Witt, W. P., Kahn, R., Fortuna, L., Winickoff, J., Kuhlthau, K., Pirraglia, P. A., \& Ferris, T. (2009). Psychological distress as a barrier to preventive healthcare among U.S. women. The Journal of Primary Prevention, 30(5), 531-547. https://doi.org/10.1007/s10935-009-0190-z

Wolch, J. R., \& Gabriel, S. A. (1984). Development and decline of servicedependent population ghettos. Urban Geography, 5(2), 111-129. https://doi.org/10.2747/0272-3638.5.2.111

Wong, Y.-L. I., \& Solomon, P. L. (2002). Community integration of persons with psychiatric disabilities in supportive independent housing: A conceptual model and methodological considerations. Mental Health Services Research, 4(1), 13-28. https://doi.org/10.1023/A:1014093008857

Wyly, E., \& Hammel, D. (2005). Mapping neo-liberal American urbanism. In R. Atkinson \& G. Bridge (Eds.), Gentrification in a Global Context: The New Urban Colonialism. London, UK: Routledge.

Yanos, P. T. (2007). Beyond "Landscapes of Despair": The need for new research on the urban environment, sprawl, and the community integration of persons with severe mental illness. Health \& Place, 13(3), 672-676. https://doi.org/10.1016/j.healthplace.2006.10.002

Ye, J., Shim, R., \& Rust, G. (2012). Health care avoidance among people with 
Serious psychological distress: Analyses of 2007 Health Information National Trends Survey. Journal of Health Care for the Poor and Underserved, 23(4), 1620-1629. https://doi.org/10.1353/hpu.2012.0189

Ziersch, A. M., Baum, F., Darmawan, I. G. N., Kavanagh, A. M., \& Bentley, R. J. (2009). Social capital and health in rural and urban communities in South Australia. Australian and New Zealand Journal of Public Health, 33(1), 7-16. https://doi.org/10.1111/j.1753-6405.2009.00332.x 
Appendix. Measures.

\section{A. Rural-Urban Continuum Codes (Urbanicity)}

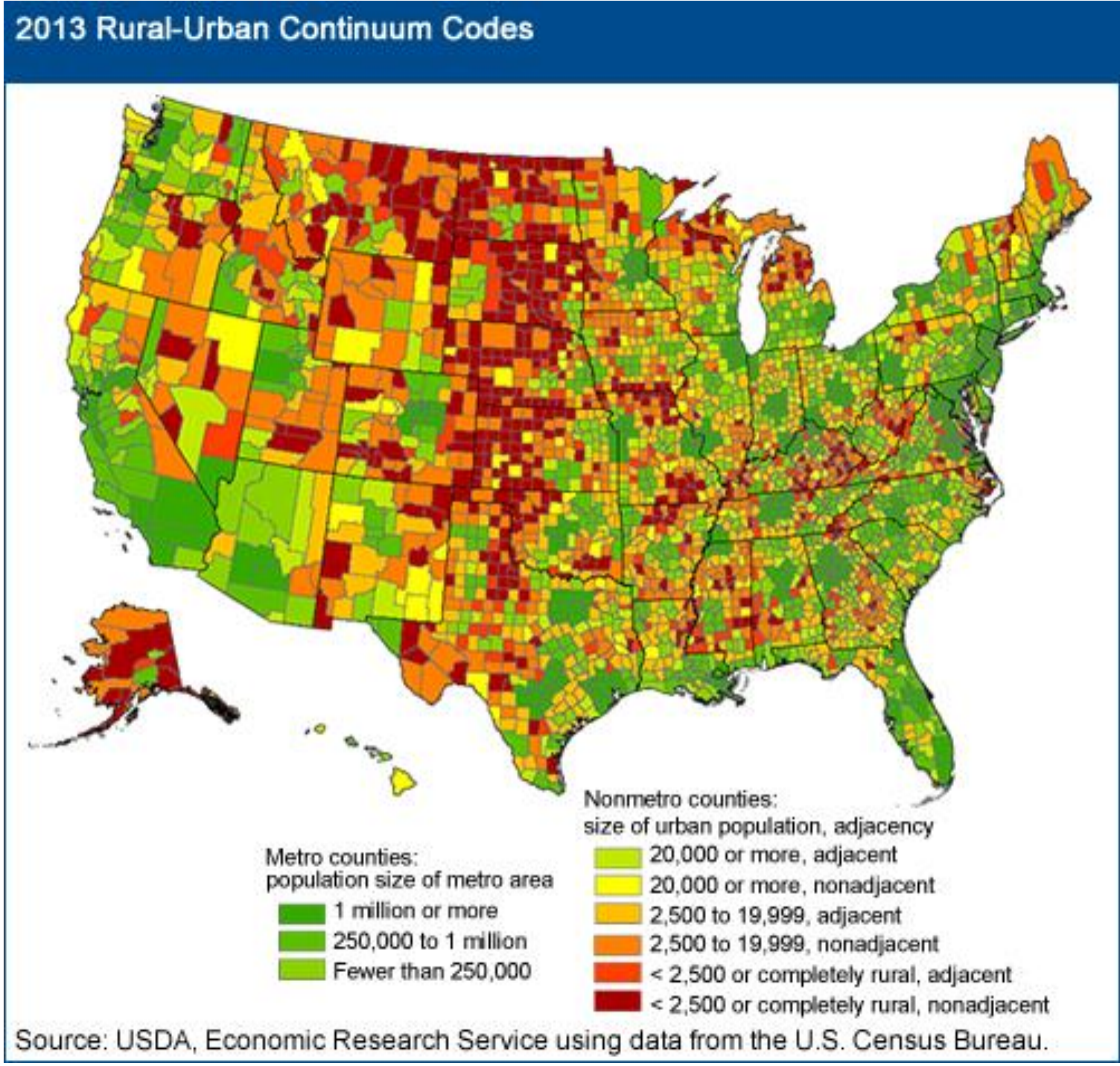




\section{B. Devaluation-Discrimination Scale (Perceived Stigma)}

Now I will ask your opinion about attitudes from community members about mental illness. Let me know how much you agree or disagree with each statement.

\begin{tabular}{|c|c|c|c|c|c|c|}
\hline \multirow[b]{2}{*}{$\begin{array}{l}\text { 1. Most people would willingly accept someone } \\
\text { with a mental illness diagnosis as a close friend }\end{array}$} & \multicolumn{6}{|c|}{$\begin{array}{l}1 \text { = Strongly Disagree } \\
2 \text { = Disagree } \\
3 \text { = Slightly Disagree } \\
4 \text { = Slightly Agree } \\
5=\text { Agree } \\
6=\text { Strongly Agree }\end{array}$} \\
\hline & 1 & 2 & 3 & 4 & 5 & 6 \\
\hline $\begin{array}{l}\text { 2. Most people believe that a person with a } \\
\text { mental illness diagnosis is just as intelligent as } \\
\text { the average person }\end{array}$ & 1 & 2 & 3 & 4 & 5 & 6 \\
\hline $\begin{array}{l}\text { 3. Most people believe that someone with a } \\
\text { mental illness diagnosis is just as trustworthy as } \\
\text { the average citizen }\end{array}$ & 1 & 2 & 3 & 4 & 5 & 6 \\
\hline $\begin{array}{l}\text { 4. Most people would accept someone with a } \\
\text { mental illness diagnosis as a teacher of young } \\
\text { children in a public school }\end{array}$ & 1 & 2 & 3 & 4 & 5 & 6 \\
\hline $\begin{array}{l}\text { 5. Most people feel that having a mental illness } \\
\text { diagnosis is a sign of personal failure }\end{array}$ & 1 & 2 & 3 & 4 & 5 & 6 \\
\hline $\begin{array}{l}\text { 6. Most people would not hire someone with a } \\
\text { mental illness diagnosis to take care of their } \\
\text { children, even if he or she is working toward } \\
\text { recovery }\end{array}$ & 1 & 2 & 3 & 4 & 5 & 6 \\
\hline $\begin{array}{l}\text { 7. Most people think less of a person who has a } \\
\text { mental illness diagnosis }\end{array}$ & 1 & 2 & 3 & 4 & 5 & 6 \\
\hline
\end{tabular}




\begin{tabular}{|c|c|c|c|c|c|c|}
\hline $\begin{array}{l}\text { 8. Most employers will hire someone with a } \\
\text { mental illness diagnosis if he or she is qualified } \\
\text { for the job }\end{array}$ & 1 & 2 & 3 & 4 & 5 & 6 \\
\hline $\begin{array}{l}\text { 9. Most employers will pass over the application } \\
\text { of someone with a mental illness diagnosis in } \\
\text { favor of another applicant }\end{array}$ & 1 & 2 & 3 & 4 & 5 & 6 \\
\hline $\begin{array}{l}\text { 10. Most people in my community would treat } \\
\text { someone with a mental illness diagnosis just as } \\
\text { they would treat anyone }\end{array}$ & 1 & 2 & 3 & 4 & 5 & 6 \\
\hline $\begin{array}{l}\text { 11. Most people would be reluctant to date } \\
\text { someone with a mental illness diagnosis }\end{array}$ & 1 & 2 & 3 & 4 & 5 & 6 \\
\hline $\begin{array}{l}\text { 12. Once community members know a person } \\
\text { has a mental illness diagnosis they will take his } \\
\text { or her opinions less seriously }\end{array}$ & & 1 & 2 & $\begin{array}{c}3 \\
6\end{array}$ & 4 & 5 \\
\hline
\end{tabular}




\section{Hopkins Symptom Checklist (Psychological Distress)}

I will now read a list of problems and complaints that people sometimes have.

Please tell me how much each problem has bothered or distressed you during the past week, including today.

\begin{tabular}{|l|c|c|c|c|}
\hline $\begin{array}{l}\text { How bothered or distressed have } \\
\text { you been during the past week by . }\end{array}$ & $\begin{array}{c}\text { Not at } \\
\text { All }\end{array}$ & $\begin{array}{l}\text { A } \\
\text { Little }\end{array}$ & $\begin{array}{c}\text { Quite } \\
\text { a Bit }\end{array}$ & Extremely \\
\hline 1.Being scared for no reason? & 1 & 2 & 3 & 4 \\
\hline 2. Feeling fearful? & 1 & 2 & 3 & 4 \\
\hline 3. Faintness? & 1 & 2 & 3 & 4 \\
\hline 4. Nervousness? & 1 & 2 & 3 & 4 \\
\hline 5. Heart racing? & 1 & 2 & 3 & 4 \\
\hline 6. Trembling? & 1 & 2 & 3 & 4 \\
\hline 7. Feeling tense? & 1 & 2 & 3 & 4 \\
\hline 8. Headache? & 1 & 2 & 3 & 4 \\
\hline 9. Feeling panic? & 1 & 2 & 3 & 4 \\
\hline 10. Feeling restless? & 1 & 2 & 3 & 4 \\
\hline 11. Feeling low in energy? & 1 & 2 & 3 & 4 \\
\hline 12. Blaming oneself? & 1 & 3 & 4 \\
\hline 13. Crying easily? & 1 & 2 & 4 \\
\hline
\end{tabular}




\begin{tabular}{|l|c|c|c|c|}
\hline 14. Losing sexual interest? & 1 & 2 & 3 & 4 \\
\hline 15. Feeling lonely? & 1 & 2 & 3 & 4 \\
\hline 16. Feeling hopeless? & 1 & 2 & 3 & 4 \\
\hline 17. Feeling blue? & 1 & 2 & 3 & 4 \\
\hline 18. Thinking of ending one's life? & 1 & 2 & 3 & 4 \\
\hline 19. Feeling trapped? & 1 & 2 & 3 & 4 \\
\hline 20. Worrying too much? & 1 & 2 & 3 & 4 \\
\hline 21. Feeling no interest in things? & 1 & 2 & 3 & 4 \\
\hline $\begin{array}{l}\text { 22. Feeling that everything is an } \\
\text { effort? }\end{array}$ & 1 & 2 & 3 & 4 \\
\hline 23. Worthless feeling? & 1 & 2 & 3 & 4 \\
\hline 24. Poor appetite? & 1 & 2 & 3 & 4 \\
\hline 25. Sleep disturbance? & 1 & 2 & 3 & 4 \\
\hline
\end{tabular}




\section{Sense of Community Index - 2 (Sense of Community)}

Please think about your broader community for these questions. We have been talking a lot about your neighborhood, but now l'd like you to think about your community, as in Portland, Gresham, etc.

How important is it to you to feel a sense of community with community members?

\begin{tabular}{|c|c|c|c|c|c|}
\hline $\begin{array}{c}\text { Prefer not } \\
\text { to part of } \\
\text { this } \\
\text { community }\end{array}$ & $\begin{array}{c}\text { Not } \\
\text { important } \\
\text { at all }\end{array}$ & $\begin{array}{c}\text { Not very } \\
\text { important }\end{array}$ & $\begin{array}{c}\text { Somewhat } \\
\text { important }\end{array}$ & Important & $\begin{array}{c}\text { Very } \\
\text { important }\end{array}$ \\
\hline 1 & 2 & 3 & 4 & 5 & 6 \\
\hline
\end{tabular}

How well do each of the following statements represent how you FEEL about this community?

\begin{tabular}{|c|c|c|c|c|}
\hline \multirow[b]{2}{*}{$\begin{array}{l}\text { 1. I get important needs of mine met because I am } \\
\text { part of this community }\end{array}$} & \multicolumn{4}{|c|}{$\begin{array}{l}1=\text { not } \text { at all } \\
2=\text { somewhat } \\
3=\text { mostly } \\
4=\text { completely }\end{array}$} \\
\hline & 1 & 2 & 3 & 4 \\
\hline $\begin{array}{l}\text { 2. Community members and I value the same } \\
\text { things }\end{array}$ & 1 & 2 & 3 & 4 \\
\hline $\begin{array}{l}\text { 3. Being a member of this community makes me } \\
\text { feel good }\end{array}$ & 1 & 2 & 3 & 4 \\
\hline $\begin{array}{l}\text { 4. When I have a problem, I can talk about it with } \\
\text { members of this community }\end{array}$ & 1 & 2 & 3 & 4 \\
\hline
\end{tabular}




\begin{tabular}{|c|c|c|c|c|}
\hline 5. I can trust people in this community & 1 & 2 & 3 & 4 \\
\hline $\begin{array}{l}\text { 6. I know a number of people in this community } \\
\text { well enough to say hello and have them say hello } \\
\text { back }\end{array}$ & 1 & 2 & 3 & 4 \\
\hline $\begin{array}{l}\text { 7. I put a lot of time and effort into being part of this } \\
\text { community }\end{array}$ & 1 & 2 & 3 & 4 \\
\hline $\begin{array}{l}\text { 8. I care about what other community members } \\
\text { think of me }\end{array}$ & 1 & 2 & 3 & 4 \\
\hline 9. I have influence over what this community is like & 1 & 2 & 3 & 4 \\
\hline $\begin{array}{l}\text { 10. If there is a problem in this community, } \\
\text { members can get it solved }\end{array}$ & 1 & 2 & 3 & 4 \\
\hline $\begin{array}{l}\text { 11. I am with other community members a lot and } \\
\text { enjoy being with them }\end{array}$ & 1 & 2 & 3 & 4 \\
\hline $\begin{array}{l}\text { 12. I expect to be part of this community for a long } \\
\text { time }\end{array}$ & 1 & 2 & 3 & 4 \\
\hline $\begin{array}{l}\text { 13. Members of this community have shared } \\
\text { important events together, such as holidays, } \\
\text { celebrations, or disasters }\end{array}$ & 1 & 2 & 3 & 4 \\
\hline
\end{tabular}

